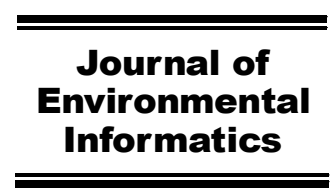

Www.iseis.org/jei

\title{
Water Quality Management of a Cold Climate Region Watershed in Changing Climate
}

\author{
N. K. Shrestha and J. Wang* \\ Athabasca River Basin Research Institute (ARBRI), Athabasca University, 1 University Drive, Athabasca, Alberta, Canada T9S $3 A 3$
}

Received 21 June 2017; revised 07 March 2018; accepted 19 April 2018; published online 15 Feburary 2018

\begin{abstract}
Cold climate regions provide a multitude of ecosystem services. However, cold regions under a changing climate could be more vulnerable than others because their glaciers, freezing soils and peatlands are sensitive to the slightest of changes in climate. This has posed serious threats to the water resources, sustainable goods production and ecosystem services that depend on regional water quality. Therefore, proper watershed management is imperative. In this paper, we investigate this issue in a cold climate watershed in central Alberta, Canada with the main objective of quantifying the impacts of climate change on water quality status. We modified specific water quality related processes of a process-based model - Soil and Water Assessment Tool (SWAT) with a view of better representing the reality of cold climate regions. A SWAT model is then built-up, followed up by a multi-site and multi-objective (streamflow, sediment and water quality) calibration, validation and uncertainty analysis in a baseline period (1983 - 2013). The calibrated and validated model is then fed with a high spatial resolution $(25 \mathrm{~km})$ daily future climate data - the CanRCM4. Improvements on stream water temperature $(T s)$ and dissolved oxygen $(D O)$ simulations justified the modifications. This model is able to simulate the dynamics of other water quality variables (carbonaceous biochemical oxygen demand $-c B O D$, total nitrogen $-T N$ and phosphorus $T P$ ) with a wide range of accuracy (very good to satisfactory) in the base period. Agriculture areas account for the highest amount of annual $T N(11.16 \mathrm{kgN} / \mathrm{ha})$ and $T P(2.88 \mathrm{kgP} / \mathrm{ha})$ yield rate in the base period leading to poor water quality status in the immediate downstream reaches. The situation would be further exacerbated $(16.52 \mathrm{kgN} / \mathrm{ha}$ and $4.89 \mathrm{kgP} / \mathrm{ha})$ in future. Finally, we tested different alternative management options to compare the water quality status of the Athabasca River Basin (ARB) under a changing climate. Significant reduction in future nutrient concentrations $(\sim 20 \%$ on $T N$ and $60 \%$ on $T P)$ can be achieved using a certain combination of management practices and the ecological status of the basin can be improved. This demonstrates that the modified SWAT model can be applied to other cold climate regions, and that the results can be translated to help in managing the ARB in a more holistic way.
\end{abstract}

Keywords: cold climate region, Athabasca river basin, water quality, climate change, SWAT, CanRCM4

\section{Introduction}

Recent observations show ample evidence of climate change impacts on the environment and ecosystems (IPCC, 2007; IPCC, 2014) of cold climate regions. For example, in Canada, increases in annual air temperature, annual precipitation and permafrost temperature, shifts in precipitation types (decreasing snowfall and increasing rainfall), a decrease in snow cover, and shrinking glaciers (ECCC, 2016) are testimonials to this, and the trend is likely to further exacerbate in the future. As a result, economic, natural ecosystems, and human health could be impacted (GoC, 2014). There is growing realization that adaptation is necessary and focus is being drawn on improving the resilience of individuals and societies to climate extremes, and on enhancing their ability to thrive in such adverse conditions (Eyzaguirre and Warren, 2014).

Specific to the Athabasca River Basin (ARB) in Alberta,

* Corresponding author. Tel.: +1-780-394-4883; fax: +1-780-497-3411.

E-mail address: junyew@athabascau.ca (J. Wang).

ISSN: 1726-2135 print/1684-8799 online

(C) 2020 ISEIS All rights reserved. doi:10.3808/jei.201900407
Canada, climate change may cause serious issues for ecosystem services and sustainability such as terrestrial carbon storage, climate regulation, water retention and infiltration, and biodiversity (ETCW, 2010; GoC, 2014; Lemmen et al., 2014; Eum et al., 2017; Shrestha et al., 2017a). Studies have indeed shown that rising annual air temperatures in the basin have led to several undesirable changes such as earlier spring freshet (Eum et al., 2017), glacier retreat and reduced snow cover (ETCW, 2010; Warren and Lemmen, 2014), increased permafrost temperatures (Bush et al., 2014), and increased green water flow and decreased green water storage (Shrestha et al., 2017a). Similarly, increased precipitation and changes in patterns (from snowfall to rainfall) have brought higher incidence of flooding in the basin (Toth et al., 2006; Eum et al., 2017; Shrestha et al., 2017a;). Consequently, higher rates of erosion and increased sediment transport through the basin's river reaches are expected (Walling, 2009). These alterations would cause substantial changes to physical and chemical properties of river water, which could be detrimental to the aquatic ecosystems' biodiversity (ETCW, 2010). For example, increasing air temperature would lead to decreased oxygen level concentrations in rivers (Pietroniro et al., 1998). Sim- 
ilarly, elevated temperatures would create disturbances on fish spawning and distribution (Campbell et al., 2014). Further, higher incidence of flooding would lead to natural water contaminations (Andrey et al., 2014). Moreover, extreme rainfall events could lead to increased erosion and would carry high amounts of organic material, nutrients (Neitsch et al., 2011) and faecal bacteria (Shrestha et al., 2014) into the receiving waters, thereby reducing its use for some purposes. Furthermore, a higher load of phosphorus would lead to eutrophication (Carlson, 1977) and higher nitrogen loads might cause hypoxia (Goolsby, 2000). Hence, there exist complex interactions and interplay between physical, chemical, and biological characteristics of water quality as they are influenced by "exogenous factors" such as hydrology and meteorology (He, 2017), and this issue need to be explored in changing climate as their impacts would, in general, exacerbate (Tong et al., 2007) and vary in different regions and water bodies (Xia et al., 2015).

Based on the recent observations (AEP, 2016), the water quality status of the ARB has been reported to vary from "fair" to "good" at different locations (AEP, 2017). However, these measurements might have missed extreme events and, it is impossible to measure the results of future events, such as a changing climate. Therefore, it is necessary to develop a model capable of continuous, long-term simulation of various basin processes including water quality. This model can be then used for the water quality assessment and management of the basin in present and future cases. Further, alternative management scenarios can be tested in view of restoring or improving the water quality status of the basin. As for the ARB, there have been some model-based assessments of climate induced alterations done recently, such as changes in streamflow (Toth et al., 2006; Kerkhoven and Gan, 2011; Leong and Donner, 2015;), shifts in seasonal streamflow pa- tterns (Eum et al., 2017), and changes in green and blue water resources (Shrestha et al., 2017a). However, to the best of our knowledge, no studies have been reported on climate induced changes in the water quality status of the basin. Thus, the primary objective of this study is to quantify the impacts of climate change on the ecological status of the basin and evaluate the effectiveness of alternative management options in view of restoring or improving the water quality status of the

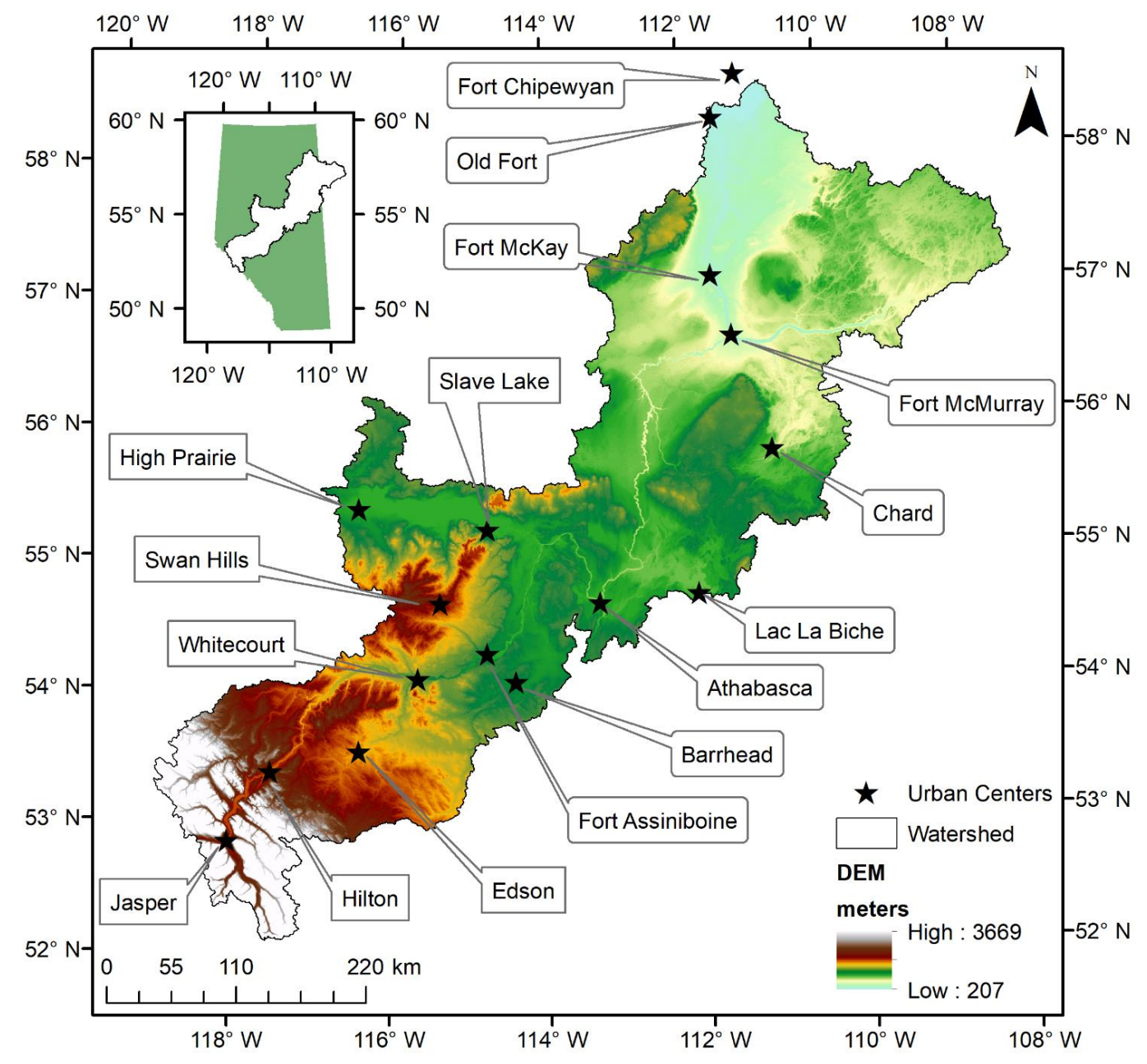

Figure 1. The location of Athabasca River Basin (ARB) in the Alberta province of Canada. Also shown are the major urban centers within the basin and the digital elevation model (DEM) of the basin. 
basin. The secondary objective is to build up a process-based hydrologic and water quality model-the Soil and Water Assessment Tool (SWAT) for this cold climate region watershed.

\section{Materials and Methods}

\subsection{Study Area}

The Athabasca River (Figure 1) flows through the heart of Northern Alberta in Canada. The river, originating from the Columbia Icefields in the Rocky Mountains, flows northeast for a distance of about $1500 \mathrm{~km}$, eventually draining into Lake Athabasca. It is drained by an area of about $160,000 \mathrm{~km}^{2}$, including several various urban centers (AWC, 2011). The elevation range of the basin is about $200 \sim 3700 \mathrm{~m}$ (Figure 1). Forest is the dominant land-use type with a coverage of more than $80 \%$ of the basin. The major activities in the basin include forestry, agriculture, coal, traditional oil and gas extraction, oil-sands mining and pulp mills (AWC, 2013). The annual average precipitation in the basin is about $510 \mathrm{~mm}$, of which about $75 \%$ is lost as evapotranspiration (Faramarzi et al., 2017; Shrestha et al., 2017a). The average monthly flows of the Athabasca river below Fort McMurray is about 575 $\mathrm{m}^{3} / \mathrm{s}$ (WSC, 2016). The low flows typically occur in February (monthly average of about $150 \mathrm{~m}^{3} / \mathrm{s}$ at Athabasca river below Fort McMurray) and peak flows in July (monthly average of about $1330 \mathrm{~m}^{3} / \mathrm{s}$ at Athabasca river below Fort McMurray). While croplands are the main source of diffused pollution, the river is also receives effluents of several waste water treatment plants and industries (AWC, 2014).

\subsection{The Simulator - Soil and Water Assessment Tool (SWAT)}

The SWAT, developed originally by the US Department of Agriculture (USDA), is a semi-distributed hydrological model typically used for long term simulation of various processes such as hydrology, erosion and sediment yield, water quality, pesticides, and bacterial activities (Arnold et al., 1998). It is one of the most widely used models in river basin planning and management, including water quality issues (Arnold et al., 2012). The SWAT model requires a spatial dataset of elevation, soil and land-use, and various meteorological datasets (precipitation, temperature, etc), which are often integrated using the Geographic Information System (GIS). Typically, SWAT divides a watershed into sub-basins. The subbasins are further divided into Hydrological Response Units (HRUs), having unique combinations of soil, slope and landuse (Arnold et al., 2011). We refer to Arnold et al. (2011) for further details of the model. We endeavor to present relevant SWAT theories in the next sections.

\subsubsection{Water Quality Related Processes in SWAT}

\subsubsection{Pollution and Nutrients Runoff from Upland Catchments}

The Carbon-Nitrogen-Phosphorus (C-N-P) cycling in SWAT is simulated using one-pool soil organic matter submodel, adapted from Kemanian and Stöckle (2010) at the HRU level. SWAT maintains separate pools for residue and manure C-N-P.
The C-N-P in the pools can undergo decomposition, mineralization and immobilization. The SWAT traces two forms of inorganic nitrogen $\left(\mathrm{NO}_{3}\right.$ and $\mathrm{NH}_{4}$, Figure $\left.\mathrm{S} 1\right)$, and three pools of organic nitrogen (fresh, active and stable, Figure S1). Similarly, three pools of inorganic phosphorus (active, stable and solution, Figure S2) and three organic pools (active, stable and solution, Figure S2) are also traced (Neitsch et al., 2011). The fresh pool of organic nutrients are associated with crop residues and microbial biomass, while the active and stable pools of organic nutrients are associated with soil humus. The $\mathrm{NO}_{3}$ transport with surface, lateral and percolation is formulized to Eqn. S1 as a function of average nitrate concentration in the top soil layer, volume of the mobile water and other physical properties of soil (e.g., water content and porosity). The organic nitrogen and phosphorus (and mineral phosphorus attached to sediments) loading from HRUs is estimated using a formulation of McElroy et al. (1976) as adapted by Williams and Hann (1978), and is a function of respective nutrient concentrations in the top soil layer, enrichment ratio and sediment yield (Equations S2 and S4). The enrichment ratio can be dynamically calculated as a function of sediment yield and surface runoff using the formulation of Menzel (1980) or kept fixed. The soluble form of phosphorus transported in surface runoff is a function of phosphorus-soil partitioning coefficient, a concentration of soluble phosphorus in the top soil layer and surface runoff volume (Equation S3). The carbonaceous biochemical oxygen demand $(c B O D)$ loading in the surface runoff is formulated as per Thomann and Mueller (1987), to a function of organic carbon concentration in the top soil surface, sediment yield, enrichment ratio, and amount of runoff (Equation S5). This organic loading can deplete the oxygen concentration in surface runoff, which is initially considered to be saturated. The depletion is calculated using the first order kinetic rate (Equation S6) and the saturated oxygen level is calculated solely based on the runoff temperature (Eqn. S7), as per APHA (1985).

\subsubsection{In-stream Water Quality Conversion}

Once all the water quality constituents are transported into the river reaches, they undergo an in-stream conversion process. The SWAT uses the widely used QUAL2E principles (Brown and Barnwell, 1987) to describe the in-stream water quality conversion processes. Table S8 shows the stoichiometric matrix of the QUAL2E, which considers fifteen processes in nine components. It should however be noted that the shortcomings of the QUAL2E formulation, such as not considering the pelagic bacteria, not respective the mass balance of constituents, etc., have widely been reported (Reichert et al., 2001). To overcome these shortcomings, Reichert et al. (2001) proposed a new conversion process principle, known as the RWQM1 formulation, which has addressed all the shortcomings of the QUAL2E formulation and thus considered to have a solid theoretical background. However, as the formulation has introduced several extra state variables, and most of these variables are not generally considered in regular river water quality monitoring programs, the formulation's application is rather difficult (Broekhuizen et al., 2012; Shrestha et al., 2017b). 
2.2.2. Modification of SWAT Model for Cold Climate Regions

It is well-known that the stream water temperature $(T S)$ is an important factor controlling in-stream water quality conversion process in river waters. Therefore, accurate estimation of stream water temperature $(T s)$ is essential as it can affect water quality dynamics profoundly (Marzadri et al., 2013). Although the stream water temperature is dependent on many factors or processes, such as atmospheric conditions, topography, stream discharge and streambed conditions, the heat exchange process at the air-water interface would be one of the most important factors (Caissie, 2006). Hence, it is evident that the stream water temperature $(T S)$ is linearly regressed as a function of air temperature $(\mathrm{Ta})$ as an approximation of the heat exchange process, such as using the linear relationship:
$T_{s}=a+b^{*} T_{a}$

where $T_{s}$ and $T_{a}$ are the stream water and air temperatures, respectively $\left({ }^{\circ} \mathrm{C}\right)$, and $a$ and $b$ are constants.

Such a simple regression is somewhat successful in catching the heat transfer physics, and is used in the original SWAT model. Because of its simplicity, the simple regression is increasingly being used (Mohseni and Stefan, 1999; Webb et al., 2008). However, Mohseni et al. (1998) observed their inability to determine the stream water temperatures all year round. They also found that the linear regression predicted the $T s$ better when the $T a$ is above $0^{\circ} \mathrm{C}$. When the $T a$ is higher (> $\left.25^{\circ} \mathrm{C}\right)$ and lower $\left(<0{ }^{\circ} \mathrm{C}\right)$, the linear relationship may cause significant errors. This is because the heat exchange process at

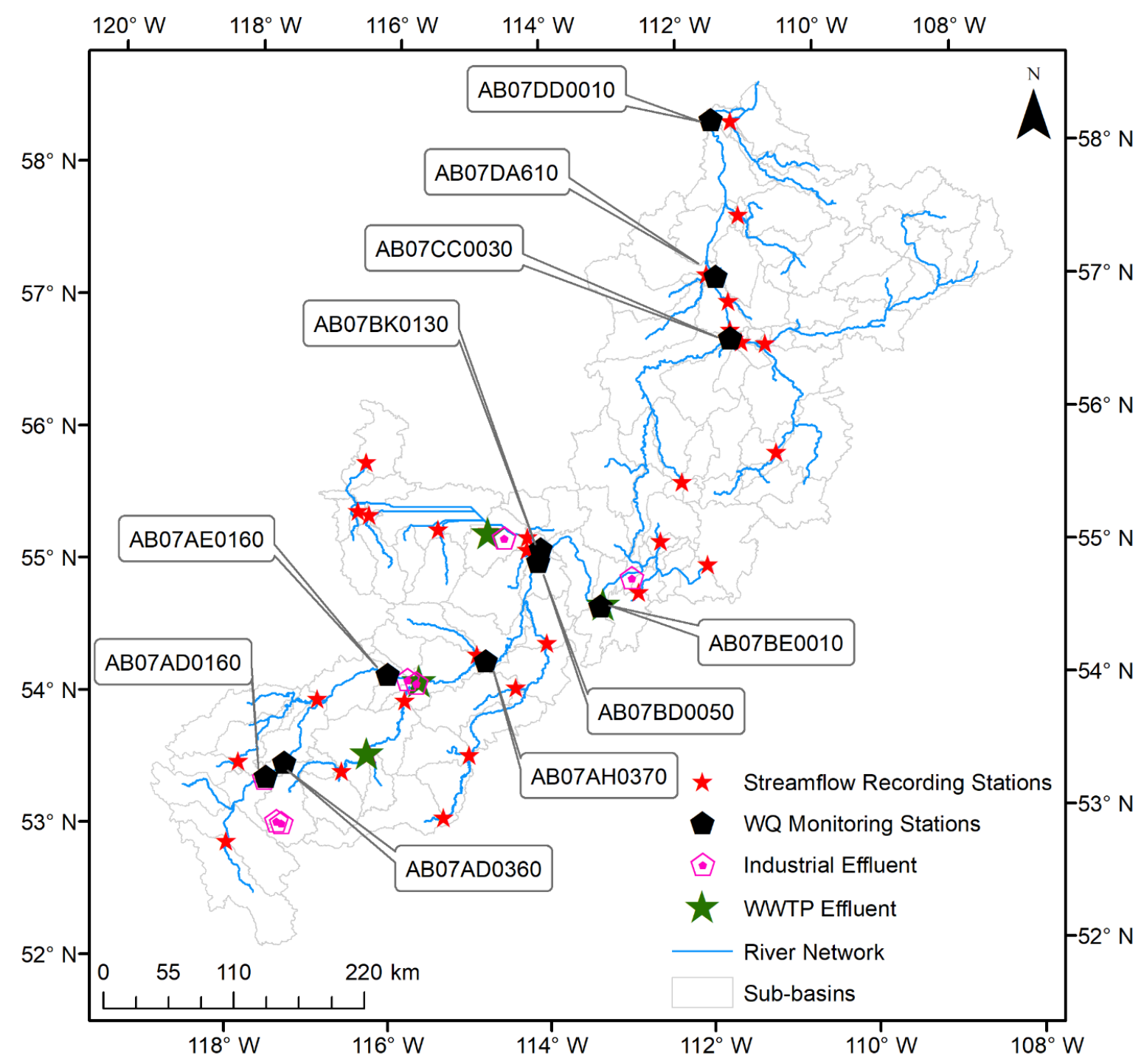

Figure 2. The Athabasca River Basin (ARB) with generated sub-basins boundaries and river network. Also shown are the point pollution sources (Industrial and Waste Water Treatment Plant-WWTP), streamflow and water quality monitoring stations across the basin. 
Table 1. Water Quality Related Parameters Considered for Sensitivity Analysis with Default, Maximum and Minimum Parameters Values

\begin{tabular}{|c|c|c|c|c|c|}
\hline Name & Description & Unit & $\begin{array}{l}\text { Max. } \\
\text { value }\end{array}$ & $\begin{array}{l}\text { Min. } \\
\text { value }\end{array}$ & $\begin{array}{l}\text { Default } \\
\text { value }\end{array}$ \\
\hline v_BIOMAX.mgt & Biological mixing efficiency & - & 0 & 1 & 0.2 \\
\hline v_CMN.bsn & Rate factor for humus mineralization of active organic nutrients & - & 0.001 & 0.003 & 0.003 \\
\hline$v_{\text {__RSDCO.bsn }}$ & Residue decomposition coefficient & - & 0.02 & 0.1 & 0.05 \\
\hline $\mathrm{v} \_$CDN.bsn & Denitrification exponential rate coefficient & - & 0 & 3 & 1.4 \\
\hline v_N_UPDIS.bsn & Nitrogen uptake distribution parameter & - & 0 & 100 & 20 \\
\hline v_P_UPDIS.bsn & Phosphorus uptake distribution parameter & - & 0 & 100 & 20 \\
\hline v__NPERCO.bsn & Nitrate percolation coefficient & - & 0.01 & 1 & 0.2 \\
\hline v__PPERCO.bsn & Phosphorus percolation coefficient & $10 \mathrm{~m}^{3} / \mathrm{Mg}$ & 10 & 17.5 & 10 \\
\hline v_PHOSKD.bsn & Phosphorus soil partitioning coefficient & $\mathrm{m}^{3} / \mathrm{Mg}$ & 100 & 200 & 175 \\
\hline v_PSP.bsn & Phosphorus availability index & - & 0.01 & 0.7 & 0.4 \\
\hline v_ERORGN.hru & Organic $\mathrm{N}$ enrichment ratio & - & 0 & 5 & 0 \\
\hline v_ERORGP.hru & Organic $\mathrm{P}$ enrichment ratio & - & 0 & 5 & 0 \\
\hline $\mathrm{v} \_$RS2.swq & $\begin{array}{l}\text { Benthic (sediment) source rate for dissolved phosphorus in the } \\
\text { reach at } 20^{\circ} \mathrm{C}\end{array}$ & $\begin{array}{l}\mathrm{mgDisP} / \mathrm{m}^{2} \\
\text { day }\end{array}$ & 0.001 & 0.1 & 0.05 \\
\hline v_RS3.swq & Benthic source rate for $\mathrm{NH} 4-\mathrm{N}$ in the reach at $20^{\circ} \mathrm{C}$ & $\begin{array}{l}\mathrm{mgNH} 4-\mathrm{N} / \\
\mathrm{m}^{2} \cdot \text { day }\end{array}$ & 0 & 1 & 0.5 \\
\hline v_RS4.swq & Rate coefficient for organic $\mathrm{N}$ settling in the reach at $20^{\circ} \mathrm{C}$ & 1/day & 0.001 & 0.1 & 0.05 \\
\hline v_RS5.swq & Organic phosphorus settling rate in the reach at $20^{\circ} \mathrm{C}$ & $1 /$ day & 0.001 & 0.1 & 0.05 \\
\hline v_RK1.swq & $\begin{array}{l}\text { Carbonaceous biochemical oxygen demand deoxygenation rate } \\
\text { coefficient in the reach at } 20^{\circ} \mathrm{C}\end{array}$ & 1/day & 0.02 & 3.4 & 1.71 \\
\hline $\mathrm{v} \_$RK2.swq & $\begin{array}{l}\text { Oxygen reaeration rate in accordance with Fickian diffusion in the } \\
\text { reach at } 20^{\circ} \mathrm{C}\end{array}$ & $1 /$ day & 0.01 & 100 & 50 \\
\hline v_RK3.swq & $\begin{array}{l}\text { Rate of loss of carbonaceous biochemical oxygen demand } \\
\text { due to settling in the reach at } 20^{\circ} \mathrm{C}\end{array}$ & 1/day & -0.36 & 0.36 & 0.36 \\
\hline v_RK4.swq & Benthic oxygen demand rate in the reach at $20^{\circ} \mathrm{C}$ & $\mathrm{mgO}_{2} / \mathrm{m}^{2} \cdot$ day & 0 & 100 & 2 \\
\hline v_BC1.swq & $\begin{array}{l}\text { Rate constant for biological oxidation of } \mathrm{NH} 4 \text { to } \mathrm{NO} 2 \text { in the reach } \\
\text { at } 20^{\circ} \mathrm{C}\end{array}$ & 1/day & 0.1 & 1 & 0.55 \\
\hline $\mathrm{v} \_\mathrm{BC} 2 . \mathrm{swq}$ & $\begin{array}{l}\text { Rate constant for biological oxidation of } \mathrm{NO} 2 \text { to } \mathrm{NO} 3 \text { in the reach } \\
\text { at } 20^{\circ} \mathrm{C}\end{array}$ & $1 /$ day & 0.2 & 2 & 1.1 \\
\hline v_BC3.swq & $\begin{array}{l}\text { Rate constant for hydrolysis of organic N to NH4 in the reach at } \\
20^{\circ} \mathrm{C}\end{array}$ & $1 /$ day & 0.2 & 0.4 & 0.21 \\
\hline $\mathrm{v} \_$_BC4.swq & $\begin{array}{l}\text { Rate constant for mineralization of organic } \mathrm{P} \text { to dissolved } \mathrm{P} \text { in the } \\
\text { reach at } 20^{\circ} \mathrm{C}\end{array}$ & $1 /$ day & 0.01 & 0.7 & 0.35 \\
\hline$v_{\_} \ldots . g w$ & Minimum observed stream water temperature & ${ }^{\circ} \mathrm{C}$ & -1 & 1 & 0 \\
\hline $\mathrm{v} \_\alpha . g w$ & Maximum observed stream water temperature & ${ }^{\circ} \mathrm{C}$ & 20 & 30 & 25 \\
\hline $\mathrm{v} \_\gamma \cdot \mathrm{gw}$ & Slope of inflection point & - & 0.15 & 0.25 & 0.2 \\
\hline $\mathrm{v} \_\beta . g \mathrm{w}$ & Stream water temperature at inflection point & ${ }^{\circ} \mathrm{C}$ & 10 & 15 & 12 \\
\hline $\mathrm{v} \_\psi \cdot g \mathrm{gw}$ & Reaeration coefficient adjustment factor & - & 0 & 1 & 0 \\
\hline \multicolumn{6}{|c|}{$\mathrm{v}=$ parameter value is replaced by given value } \\
\hline
\end{tabular}

the air-water interface is non-linear due to other influences, such as the presence of hysteresis in the stream-air temperature relationship (Webb et al., 2003), and wind speed, among others. In cold climate regions like the ARB, it is common that the $T a$ is below freezing for most of the year. A non-linear equation is thus more suitable for such regions. We adopted a nonlinear relationship between $T s$ and $T a$ (Equation 2), as suggested by Mohseni et al. (1998). Many studies have shown that this is more accurate in cold climate regions (Mohseni et al., 1998; Shrestha et al., 2013b; Laanaya et al., 2017):

$T_{s}=\mu+\frac{\alpha-\mu}{1+e^{\gamma\left(\beta-T_{a}\right)}}$ where $\mu$ is the minimum observed stream water temperature $\left({ }^{\circ} \mathrm{C}\right), \alpha$ the maximum observed stream water temperature $\left({ }^{\circ} \mathrm{C}\right)$, the slope of inflection point (-) and $\beta$ the stream water temperature at the inflection point $\left({ }^{\circ} \mathrm{C}\right)$.

In cold climate regions, seasonal ice coverages are also an important factor for the river water quality dynamics (Prowse, 2001; Shakibaeinia et al., 2016). For example, ice coverage can limit oxygen exchange at the air-water interface. In the ARB, the study by HydroQual-Consultants (1989) indicated that the air-water oxygen exchange could be close to zero in winter months. Therefore, it is often necessary to robustly quantify the ice formation and melt at the river surface. 
In this study, we introduced a seasonality factor to correct the air-water oxygen exchange using Equation 3, which in the original SWAT has been kept constant (to a value of zero) irrespective of the time of the year. By introducing the factor, $\psi$, we are able to limit/inhibit the air-water oxygen exchange the re-aeration process (RK2, process 1, Table S8) during the ice-covered season. Such an approach has been used by other researchers, (e.g., Shakibaeinia et al., 2016):

$$
R K_{2}{ }^{\prime}=R K_{2}(1-\psi)
$$

where $R K_{2}{ }^{\prime}$ is the modified reaeration coefficient (1/day), $R K_{2}$ the original reaeration coefficient (1/day), and $\psi$ the seasonality adjustment factor (-). Obviously, value of the factor would oscillate between 0 (full re-aeration) and 1 (complete inhibition). Furthermore, the factor, being a physically based parameter, should be assigned as per field conditions. For instance, if the entire river width is totally covered with snow, there would be no exchange of oxygen between water column and atmosphere, hence, should be assigned as 1.0. Similarly, if there are no traces of snow in river's entire width, the factor should be assigned a value of 0.0 , thereby allowing a complete exchange of oxygen. In other conditions, values can be varied from 0 to 1 , subjected to calibration based on dissolved oxygen concentrations/load.

\subsection{Model Inputs and Built-up}

\subsubsection{General Databases}

Three sets of spatial data were pre-processed as required by the SWAT model. They included: (a) Digital Elevation Model (DEM), for which we used hole-filled SRTM DEM (Jarvis et al., 2008); (b) land use, which was adopted from Global Land Cover Characterization (Loveland et al., 2000) with spatial scale of $1 \times 1 \mathrm{~km}$; and (c) soil map, which was based on Agriculture and Agri-Food Canada (SLCWG, 2010) with spatial scale of 1:1 million. Sub-basins and stream network based on the DEM with a threshold area of $200 \mathrm{~km}^{2}$ were delineated. Further, sub-basin outlets were also defined at 10 gauging stations of water quantity and quality, as required at the major river confluences (Figure 2). This process resulted in a total of 131 sub-basins. Next, a slope map was derived from the DEM and divided into 4 classes with breaks at 5,10,15 and $20 \%$. A threshold of 10,5 and $10 \%$ for land use, soil and slope were used, as suggested by Strauch et al. (2015). These processes resulted in a total of 1370 HRUs.

Then, daily meteorological data; precipitation, maximum and minimum temperatures data at 73 stations (Figure S8), recorded by GoC (2016), and relative humidity, solar radiation, and wind speed data at 230 stations (Figure S8), recoded by CFSR (2016) were supplied to the model. Finally, the Penman-Monteith method was selected to estimate the potential evapotranspiration. Similarly, several natural and man-made impoundments were considered in the model as ponds or reservoirs, depending on whether data of their operations was available. Finally, as the basin lies in a cold climate region, and the hydrology of the basin is snow dominated, we opted to use ten elevation bands in order to account for variations of the snow-related parameters, and to allow adjustments on precipitation and temperature at higher elevations.

\subsubsection{Point and Non-point Pollution Sources}

As depicted, the basin is drained by several city centers, and hosts several industries (Figure 1). The river receives effluents from industries and the urban centers' Waste Water Treatment Plants (WWTPs). As such, seven industrial and four WWTPs effluents were incorporated in the model. They were implemented as annual constant point sources. The effluxent discharge and water quality concentration data were taken from Alberta Environment \& Parks (AEP, 2016). While the observations at these point sources showed fluctuations (Figure S3), we had to impose annual constant values due to a lack of high-resolution data (e.g., daily).

Spring Wheat and Barley are the major crops of the agriculture areas of the basin, and pasture, grassland and rangeland are the main livestock grazing areas. Therefore, they were regarded as non-point sources of pollution. Therefore, we assigned appropriate management operations for each crop type using a $30 \times 30 \mathrm{~m}$ crop inventory map (AAFC, 2013). Normal management operations data for Spring Wheat and Barley included seeding date (May 1) and harvesting date (September 15), as per AGRI-FACTS (2013). Regarding the fertilizer application dose for these crops, while the AGRIFACTS (2004) reported a wide range of values $(0 \sim 80$ pounds/ acre of Nitrogen in unirrigated land, $40 \sim 130$ pounds/ acre in irrigated land and $20 \sim 50$ pounds/acre of Phosphate $\left(\mathrm{P}_{2} \mathrm{O}_{5}\right)$, depending on previous crop and soil type), we imposed a Nitrogen application rate of 100 pounds/acre, which AGRIFACTS (2013) calculated to be economically optimal, and a Phosphate application rate of 35 pounds/acre, the latter being the average of the reported range of Phosphate application rates in the Alberta province. For pasture, one seeding date (March 15) and two harvesting dates (one in July 15 and other in October 15) were taken as per AGRI-FACTS (2005b). Fertilizer doses of four Nitrogen applications of 60 pounds/ acre on March 15, 50 pounds/acre on June 15, 50 pounds/acre on July 15 and 40 pounds/acre on August 15, and a single Phosphate application of 60 pounds/acre on March 15, were taken as per AGRI-FACTS (2005a). For grassland and rangeland, grazing operations needed to be defined. Here, we assumed that a mature cow would consume $6 \mathrm{~kg}$ of dry grass/ hectares/day, and dispose $5.5 \mathrm{~kg}$ of fresh manure/ hectares/day, as per AGRI-FACTS (1998).

\subsection{Model Evaluation in Base Period}

2.4.1. Calibration, Validation, and Sensitivity and Uncertainty Analysis

We used the sequential uncertainty fitting algorithm (SUFI-2) (Abbaspour et al., 2004) in the SWAT Calibration and Uncertainty Programs (SWAT-CUP) (Abbaspour et al., 
2007) for the model sensitivity, model calibration and validation, and uncertainty analysis. A global sensitivity analysis method of the SWAT-CUP was used for which the NashSutcliffe efficiency (NSE) was chosen as the objective function. As the water quality dynamics of a river basin are influenced by the flow as well as sediment dynamics, all the related (e.g., streamflow, sediment and water quality) parameters were considered for the sensitivity analysis. Table 1 shows the water quality related parameters considered for this purpose, while Tables S1 and S2, list the flow and (erosion and) sediment related parameters.

Once the sensitive parameters were identified, a multisite and multi-variable (streamflow, sediment and water quality) approach was adopted for the calibration and validation of the model in the base period. Two years $(1980 \sim 1981)$ of total time span $(1980 \sim 2013)$ were used as the warm-up period, 16 years $(1990 \sim 2005)$ as the calibration period, and the remaining years as the validation period. Unlike streamflow, water quality data are often not available for a long period (refer illustration in Figure S4). Therefore, selection of calibration and validation periods might be limited due to various factors such as availability and quality (e.g., long missing series) of data, and climatic condition (e.g., need to include both dry and wet years for model calibration). The SWAT-CUP with its SUFI-2 algorithm was run several times (300 500 model runs each time) and, at each time, a narrower parameter range was defined as per the "new parameter range" suggestion of the SWAT-CUP until reasonable values of goodness of fit statistics are obtained. Furthermore, two widely used statistical factors, the p-and r-factor, were optimized to quantify the uncertainty of the model results. The p-factor reflects the numbers of observations bracketed by the $95 \%$ predictive uncertainty band and the r-factor encapsulates the thickness of the band (Abbaspour et al., 2007). Ideal value of the p-and $\mathrm{r}$-factor is 1 and 0 , respectively. A higher p-factor can be obtained with the expense of higher $r$-factor. Hence, in this study, we aimed to get an r-factor of less than 1.5 as much as possible. For this, we used streamflow observations recorded at 35 gauging stations (Figure 2) by WSC (2016), and sediment and water quality variables at a maximum of 10 stations (Figure 2) recoded by AEP (2016).

\subsubsection{Model Performance Evaluation}

There exist various statistical indicators to evaluate the model performance evaluations in environmental modelling

Table 2. Goodness of fit statistics Considered for Model Evaluation of Different Variables and Range of Values of These Statistics for a Particular Qualitative Rating of Different Variables (Streamflow, Sediment and Water Quality)

\begin{tabular}{lllll}
\hline Variables & Performance Ratings & & \\
\cline { 2 - 5 } & Very Good & Good & Satisfactory & Unsatisfactory \\
\hline Streamflow & PBIAS $\leq \pm 10$ & $\pm 10 \leq$ PBIAS $\leq \pm 15$ & $\pm 15 \leq$ PBIAS $\leq \pm 25$ & PBIAS $\geq \pm 25$ \\
& $0.75<$ NSE $\leq 1.00$ & $0.65<$ NSE $\leq 0.75$ & $0.50<$ NSE $\leq 0.65$ & NSE $\leq 0.50$ \\
& $0.00<\mathrm{RSR} \leq 0.50$ & $0.50<\mathrm{RSR} \leq 0.60$ & $0.60<\mathrm{RSR} \leq 0.70$ & RSR $>0.70$ \\
Sediment & PBIAS $\leq \pm 15$ & $\pm 15 \leq \mathrm{PBIAS} \leq \pm 30$ & $\pm 30 \leq \mathrm{PBIAS} \leq \pm 55$ & PBIAS $\geq \pm 55$ \\
& $0.70<\mathrm{NSE} \leq 1.00$ & $0.60<\mathrm{NSE} \leq 0.70$ & $0.45<\mathrm{NSE} \leq 0.60$ & NSE $\leq 0.45$ \\
& $0.00<\mathrm{RSR} \leq 0.55$ & $0.55<\mathrm{RSR} \leq 0.63$ & $0.63<\mathrm{RSR} \leq 0.71$ & RSR $>0.71$ \\
Water Quality & PBIAS $\leq \pm 25$ & $\pm 25 \leq \mathrm{PBIAS} \leq \pm 40$ & $\pm 40 \leq \mathrm{PBIAS} \leq \pm 70$ & PBIAS $\geq \pm 70$ \\
Components & $0.65<\mathrm{NSE} \leq 1.00$ & $0.50<\mathrm{NSE} \leq 0.65$ & $0.35<\mathrm{NSE} \leq 0.50$ & NSE $\leq 0.35$ \\
& $0.00<\mathrm{RSR} \leq 0.60$ & $0.59<\mathrm{RSR} \leq 0.71$ & $0.71<\mathrm{RSR} \leq 0.81$ & RSR $>0.81$ \\
\hline
\end{tabular}

Table 3. Alberta River Water Quality Index (ARWQI), European Union (EU) based Objectives Values of Different Water Quality Variables, and the Ecological Status Categorization based on River Water Quality Index (WQI)

\begin{tabular}{|c|c|c|c|c|c|c|}
\hline \multicolumn{2}{|l|}{ Variable } & Symbol & Unit & ARWQI: Objectives ${ }^{1}$ & $\mathrm{EU}^{2}$ & $\mathrm{EU}^{3}$ \\
\hline \multicolumn{2}{|c|}{ Water Temperature } & Ts & ${ }^{\circ} \mathrm{C}$ & & $<21.5$ & $<28$ \\
\hline \multicolumn{2}{|c|}{ Carbonaceous Biological Oxygen Demand } & CBOD & $\mathrm{mg} \mathrm{O}_{2} / \mathrm{L}$ & $>6.5$ & $>9$ & $>7$ \\
\hline \multicolumn{2}{|c|}{ Total Nitrogen } & $\mathrm{TN}$ & $\mathrm{mg} \mathrm{N} / \mathrm{L}$ & $<0.05$ & & \\
\hline \multicolumn{2}{|c|}{ Total Phosphorus } & $\mathrm{TP}$ & $\mathrm{mg} \mathrm{P} / \mathrm{L}$ & & & \\
\hline \multicolumn{7}{|c|}{${ }^{1}$ Alberta River Water Quality Index Objective Level, monthly frequency (AEP, 2017) } \\
\hline \multicolumn{7}{|c|}{${ }^{2}$ EU Fish Water Quality Directive: 2006/44/EC (EU, 2006) - Salmonid Waters Mandatory Level } \\
\hline \multicolumn{7}{|c|}{${ }^{3}$ EU Fish Water Quality Directive: 2006/44/EC (EU, 2006) - Cyprinid Waters Fish Mandatory Level } \\
\hline \multicolumn{7}{|c|}{ Alberta River Water Quality Rating System (AEP, 2016) } \\
\hline Index Value & Rating & \multicolumn{5}{|c|}{ Description } \\
\hline $96-100$ & Excellent & \multicolumn{5}{|c|}{ The objectives are always met } \\
\hline $81-95$ & Good & \multicolumn{5}{|c|}{ The threshold values are occasionally exceeded } \\
\hline $66-80$ & Fair & \multicolumn{5}{|c|}{ The threshold values are exceeded by moderate amount } \\
\hline
\end{tabular}


(Bennett et al., 2013). It should be noted that some high frequency water quality data might not be available, particularly at extreme events mainly due to the practical difficulty of sampling such events (Shrestha et al., 2013a), which would hinder a robust model evaluation. We experienced a similar problem as nutrient ( $T N$ and $T P$ ) samples at the Athabasca River u/s of Fort McMurray during extreme wet events are scarce (Figure S4). As a result, an average statistics is often used. Furthermore, several graphical plots (e.g. time series, frequency plots, etc.) are widely used to complement this limitation.

In recent years, different qualitative ratings (very good, good, satisfactory and unsatisfactory, Table 2) have been employed based on the range of chosen statistical indicators, to qualify the model results. Here, we used three widely used statistical indicators - the percentage of bias (PBIAS), the NashSutcliffe efficiency (NSE) and the root mean squared error normalized by standard deviation of observed variable $(R S R)$. A range of values of these statistics as suggested by Moriasi et al. (2007); Moriasi et al. (2015) was used to assign a qualitative rating to the model results (Table 2). In the case of different qualitative ratings from three different statistical indicators, an average qualitative rating was calculated assigning numeric values of 1 to 4 to unsatisfactory to very good ratings.

\subsubsection{Water Quality Index (WQI) Calculation}

In order to quantify the ecological status of river water, we calculated the water quality index (WQI), as per the formulation suggested by AEP (2017). The WQI considers three water quality aspects, namely the scope (represented by $F 1$ ), frequency (represented by F2) and amplitude (represented by F3), referencing Equation 4, relative to the water quality objectives set (Table 3 ) by Alberta Environment \& Parks (AEP, 2016). Due to a lack of data, some of the objective values are adopted from EU Fish Water Quality Directive (EU, 2006). The WQI value ranges from 0 (bad quality) to 100 (best quality), and based on the ranges of the WQI, a qualitative rating (excellent to poor, Table 3) was assigned to the river water in a river reach:

$$
\begin{aligned}
& \text { Index Score }=100-\left(\frac{\sqrt{F_{1}^{2}+F_{2}^{2}+F_{3}^{2}}}{1.732}\right) \\
& F_{1}=\left(\frac{\text { No. of failed } \text { var iables }}{\text { Total No. of } \text { var iables }}\right) \times 100, \\
& F_{2}=\left(\frac{\text { No. of failed tests }}{\text { Total No. of tests }}\right) \times 100, \\
& F_{3}=\left(\frac{\text { nse }}{0.01 * \text { nse }+0.01}\right) \\
& \sum_{\text {nse }}^{n}=\frac{\sum_{i-1}^{n} \text { departure }}{\text { No.of tests }}
\end{aligned}
$$

$$
\begin{gathered}
\text { departure }_{i}=\left(\frac{\text { FailedTest }_{i}}{\text { ThresholdValue }_{i}}-1\right) \\
\text { if test value must not exceed the threshold, } \\
\text { departure }_{i}=\left(\frac{\text { ThresholdValue }_{i}}{\text { FailedTest }_{i}}-1\right) \\
\text { if test value must not fall below the threshold, } \\
\text { departure }_{i}=\text { FailedTest }_{i} \text {, if threshold is zero }
\end{gathered}
$$

where $F_{1}$ is a factor representing the number of water quality variables not meeting the objectives (-), $F_{2}$ is a factor representing the number of individual concentrations that don't meet the objectives (-), $F_{3}$ is a factor representing the amount by which these individual concentrations depart from the objectives (-), and nse is a factor representing the amount by which the water quality depart from the compliance (-).

\subsection{Model Application in Future Period}

\subsubsection{Climate Change Data}

There exists a wide variety of future climate datasets for climate impact studies. Generally, outputs from a General Circulation Models (GCMs) are statistically or dynamically downscaled to smaller regions of interests using various techniques (Wilby et al., 1998) and used for impact studies often after bias correction (Teutschbein and Seibert, 2012). For Canada, ECCC (2016) has a repository of tailored climate data and scenarios to be used for climate impact studies. In this study we opted to use the future climate projections from Canadian Center for Climate Modelling and Analysis (CCCMA), Regional Climate Model (RCM), the CanRCM4 (Scinocca et al., 2015). The temporal and spatial resolution of data is daily and $0.44 \times 0.44^{\circ}(\sim 50 \mathrm{~km})$ or $0.22 \times 0.22^{\circ}(\sim 25 \mathrm{~km})$, respectively. The higher (spatial) resolution data set $(\sim 25 \mathrm{~km})$ of several variables of interests were pre-processed for the period of $2006 \sim 2100$ at a total of 272 CanRCM4 grid points that fall within the ARB (Figure S7). They included precipitation, maximum and minimum temperature, and specific humidity (converted to relative humidity), solar radiation and wind speed. Although some researchers adopted a multimodel ensemble approach for climate change impact assessment, e.g., (Christensen and Lettenmaier, 2007), it can be argued that the projections of the CanRCM4 is tailor-made for Canadian conditions. Furthermore, in a study by Cheng et al. (2017c) involving 6 CMIP5 GCMs in the ARB, they found that "the ensemble can not outperform any GCMs". Moreover, the quality of the latest CanRCM4 dataset has been improved from its parent GCM (CanESM2) (Scinocca et al., 2015). Additionally, for Western North America region, the parent GCM (CanESM2) was found to be one of the top 3 models in terms of representing different climatic indices of the region (Murdock et al., 2013). However, we have not systematically evaluated the accuracy of different GCMs for the ARB, as done by Cheng et al. (2017b), which is indeed one of the limitations of the work. For the CanRCM4 dataset, two IPCC AR5 emission scenarios - the RCP 4.5 and the RCP 8.5 (IPCC, 2014) were considered. Similarly, two periods, a mid-century period (2040's) with a period of $2021 \sim 2060$, and a late- cen- 
tury period (2080's) with a period of $2061 \sim 2100$, were considered. Owing to the size of the basin and different landuse (Figure S5) soil and slope (Figure S6), the ARB was divided into five regions: headwaters, foothills, prairie, Lesser Slave and boreal, for the assessment of climate change impacts at different regional scales (Figure S7). We believe that consideration of different emission scenarios, different future periods and regional analysis would be helpful to reduce some of the uncertainties inherent in the climate change data and corresponding impact assessment (Hawkins and Sutton, 2009).

\subsubsection{Tested Management Scenarios}

It has been reported that the catchments in this region were expected to receive more intense precipitation leading to an increase in streamflow (Eum et al., 2017; Shrestha et al., 2017a). While a positive effect from dilution of pollutant is expected, a higher surface runoff and erosion would lead to higher pollutant and nutrients runoff to the stream. In this regard, we formulated two management scenarios in view of improving water quality status of the basin under changing climate. The first scenario (Scenario A) aimed at controlling the point pollution sources and the second (Scenario B) aimed at controlling the non-point pollution sources.

The point sources of pollution in the basin are industrial and waste water treatment plant effluents. The imposed yearly constant values of pollutants based the observations showed that they tend to cross the effluent quality limits (Figure S3), such as that imposed by the EU (1991). Here, we reduced the effluent concentrations at the maximum allowable limits (TN $=10 \mathrm{mgN} / 1, T P=1 \mathrm{mgP} / \mathrm{l}$ and $c B O D=25 \mathrm{mgO}_{2} / \mathrm{l}$ ).

As for the non-point pollution sources, we aimed at: (a) reducing fertilizer application in agricultural areas and pasture land-use, (b) managing manure at grasslands and rangelands, and (c) adopting terrace farming in agricultural areas. As stated earlier, we imposed economically optimal levels of Nitrogen application rate in agricultural areas (100 pounds of Nitrogen per acre, as suggested by AGRI-FACTS, 2013) in the baseline period. This rate was reduced to the lower limit of the range of recommended nitrogen dose (40 pounds of Nitrogen per acre) (AGRI-FACTS, 2013). Similarly, the Phosphate application rate in the base period was also reduced to the lower limit of the recommended dose (20 pounds of phosphate per acre). Next, the manure production rate of a grown cow while grazing $(5.5 \mathrm{~kg}$ of fresh manure/hectares/ day) was reduced to zero representing a situation where the manure would be properly collected and disposed. Finally, we tested the terrace farming practice in agricultural areas, as it is one of the most commonly used cropland practices in Canada (AAFC, 2002). Adopting this practice required changes in various parameters of the SWAT model. As such, we adopted different values of the universal soil loss equation crop practice factor $(\mathrm{P})$ as a function of slope, suggested by Haan et al. (1994). Similarly, the initial SCS runoff curve number for moisture condition II (TERR_CN) was set at 58 as per suggestion of Arnold et al. (2011) and the average slope length (TERR_SL) was varied with the slope (200 m for slope $<5 \%$ to $20 \mathrm{~m}$ for slope $>20 \%$ ). Effectiveness of both individual and combined scenarios $(\mathrm{A} \& \mathrm{~B})$ in improving the water quality status in future periods, was evaluated.

\section{Results and Discussion}

For clarity purposes, we have presented water quality results in this paper. As streamflow and sediment results affect water quality results (He, 2017), we refer Shrestha et al. (2017a) for details on streamflow results, and Shrestha and Wang (2018) for details on sediment yield and transport results. The goodness-of-fit statistics of the streamflow and sediment results can be found on Table S3 and S4 respectively.

While the accuracy of streamflow results varied across the basin, the model, in general, simulated streamflow dynamics of the main river in higher accuracy than small tributaries. The lower accuracy of small tributaries in the Boreal plain region is particularly concerning as the model seem to underperform in this region of the watershed (Table S3). It should be noted that SWAT is better suited to model agricultural watersheds. The Boreal plain region, which has > $90 \%$ forest coverage might have different hydrological response than agricultural watersheds. In the Boreal forests, Watson et al. (2008) incorporated "effects of slope and aspect on solar radiation", added "a litter layer storage model" and developed "a simple wetland model to represent the bogs and fens", and found better results. Similarly, in such low-lying area, the infiltration excess runoff that the SWAT model employs has been generally criticized. It is argued that the saturation excess runoff is the primary runoff generation process in such areas, leading to the so-called variable source area (VSA) phenomena (Dunne and Black, 1970). Some researchers, e.g., Easton et al. (2008) tested the VSA approach in SWAT, and found slightly better results. Similarly, use of a single (constant) spatial data set of the land use can be questioned as especially researchers, e.g., Boluwade and Madramootoo (2015) found noticeable discrepancies on streamflow when using variable land use maps. While these issues definitely need further investigation, accuracy of our results might be thus a compromise between simplification, feasibility and reality. Besides these, presence of a lower number of precipitation measuring stations at North-East part of the Boreal plain region, and significant missing data (Figure S8) might be the main reason for the model underperformance. While SWAT employs statistical weather generator to fill the missing gaps in meteorological data (Neitsch et al., 2011), generated data are always an approximation of the reality.

Similarly, accuracy of the sediment results at a particular station (Athabasca River at Windfall) is lower than that at other stations (Table S4). Note that model simulated streamflow at that station with a "very good" accuracy (Table S3). We can thus relate this particular problem to the sediment related parameters (Table S2), specifically parameter SPEXP which would be constant at all river reaches. This particular station is the only station located outside of the main Athabasca river reach. Hence, a different value of the SPEXP might have resulted in better goodness-of-fit statistics. Such 
discrepancy would be important in a large continental river basin such as the ARB, in which researchers e.g., Cheng et al., (2017a) showed presence of different climatic zones. Furthermore, a lower number of observations as compared to downstream stations also might have played a role for this. The interested readers can refer to Shrestha and Wang (2018) for further details.

\subsection{Improvement on Stream Water Temperature and Dissolved Oxygen Results}

The ability of the modified SWAT model in improving the stream water temperatures ( $T s$, Figure 3$)$ and dissolved oxygen ( $D O$, Figure 4$)$ results at selected stations was quite evident. As depicted in Section 2.4.1, we used the SWAT-CUP for parameter optimization. The optimized values of four temperature related parameters $-\mu, \alpha, \gamma$, and $\beta$ (refer Equation 2), for this particular station (Figure 3) were $-0.25,15.54,0.2$ and $9.3{ }^{\circ} \mathrm{C}$, respectively. Similarly, the seasonality factors $(\psi$, refer Equation 3) for this particular station (Figure 4) were 1.0 for the months of December to April and 0.0 for other months.

The original SWAT model could not simulate the extreme high and extreme low $T s$ while the modified SWAT model tended to represent the dynamics quite well. The improvements have been reflected in the goodness of fit statistics values. The overall quality of $T s$ results improved from "satisfactory" to "very good" after the modification. The original SWAT model tended to over- and under-estimate the high and low $T s$, respectively. In the original SWAT model, the values of coefficients of the linear relationship ( $a$ and $b$, Equation 1), are fixed at 5.0 and 0.75 , respectively. Hence, during the winter months, as the air temperatures drop below freezing, it is evident that $T s$ would be as low as $-15^{\circ} \mathrm{C}$. However, the observations indicated that the $T s$ would still be around zero, indicating non-linear relationship between $\mathrm{Ta}$ and $T s$. The non-linearity at low temperatures could be due to the release of latent heat with ice formation, which would prevent $T s$ from going below freezing (Mohseni et al., 1998; Webb et al., 2003). Similarly, for higher air temperatures (> $25{ }^{\circ} \mathrm{C}$ ), the non-linearity between the air and stream water

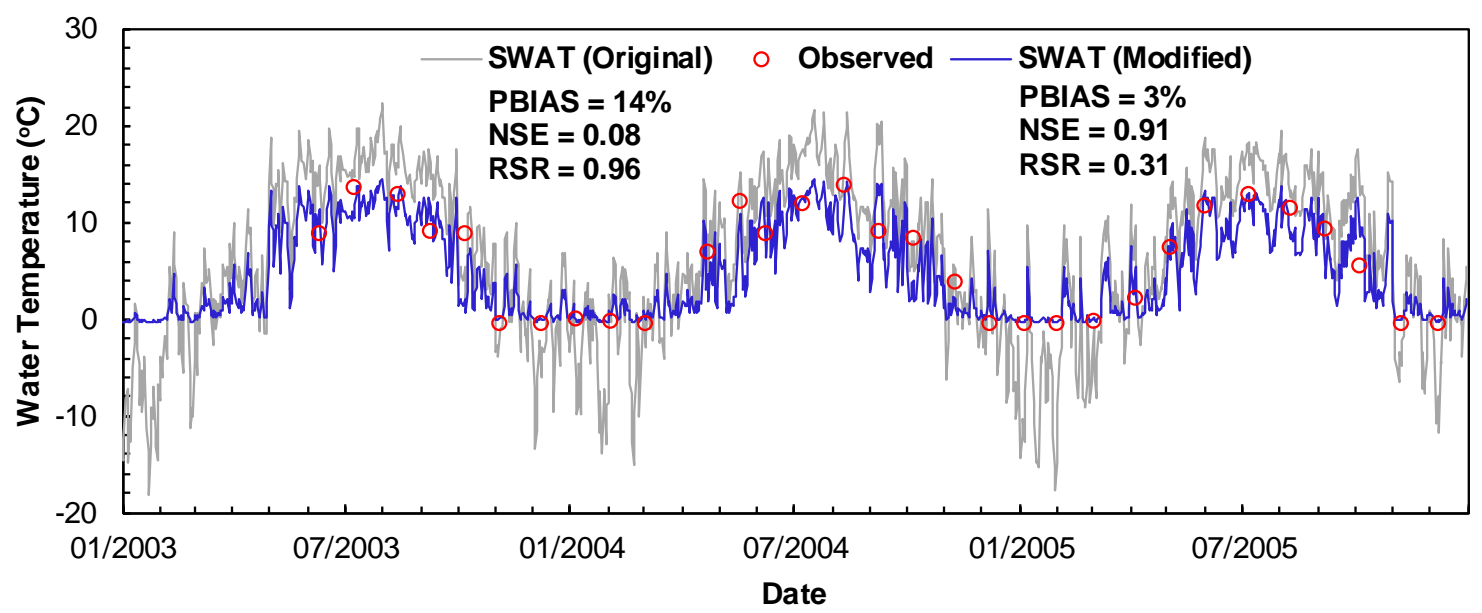

Figure 3. Stream water temperature $(T S)$ simulation results using original and modified SWAT model at an upstream station (\#AB07AD0360).

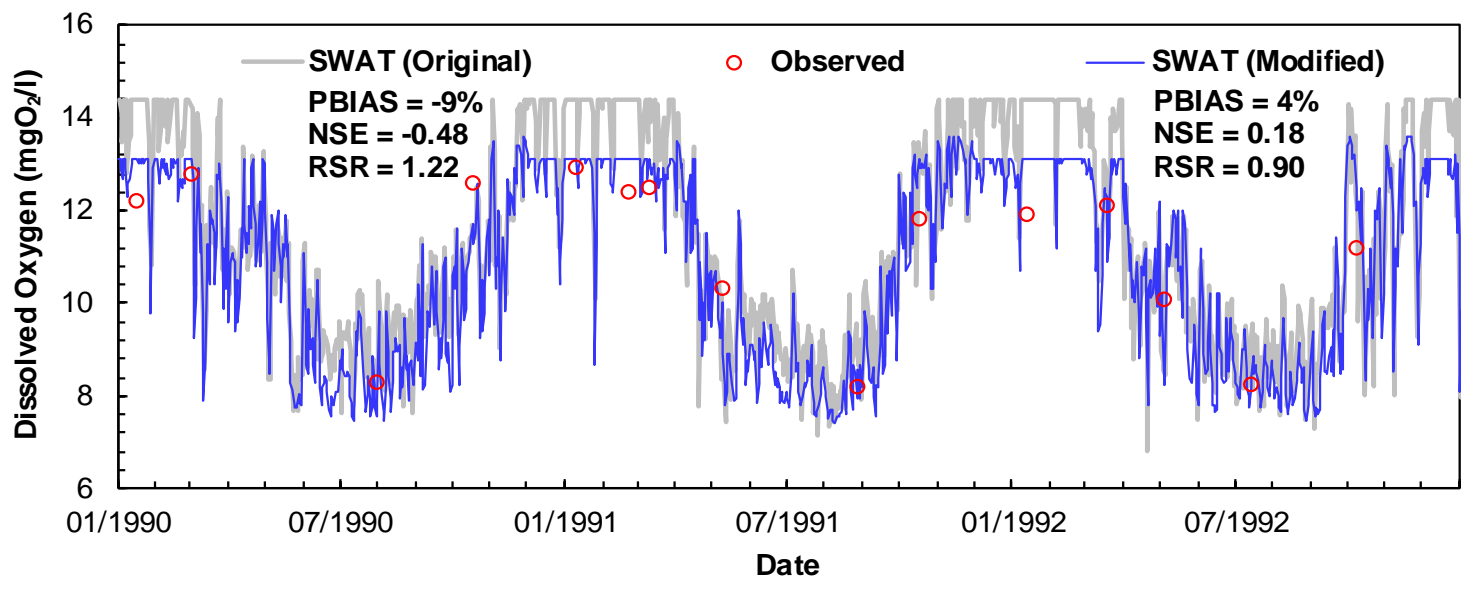

Figure 4. Dissolved oxygen $(D O)$ simulation results using original and modified SWAT model at a mid-basin station (\#AB07BD0050). 
temperatures could be due to the so-called "evaporative cooling” effect (Mohseni et al., 1998; Mohseni and Stefan, 1999). As the air temperatures increase, an increased vapor pressure deficit promotes higher evaporation from water surface and increases the evaporative cooling. Using the logistic type non-linear equation (Equation 2) in the modified SWAT model, the simulated $T s$ tend to follow the trend of observations quite well.

Similarly, for the $D O$ simulations, the positive effect of the modification was quite evident partly because of the improvements on the $T s$ simulation results, as the saturation $D O$ level is solely based on the Ts (Equation S7). As expected, allowing seasonality (Equation 3) in air-water oxygen exchange (reaeration-process 1 of Table S8), the DO level dropped quite significantly during the snow-covered winter months. The pattern of the observed $D O$ has been better represented by the simulation results of the modified SWAT. While the goodness of fit statistics indicated the satisfactory quality of model results for both cases, significant improvements on the individual statistics has been achieved (e.g., NSE $=0.18$ from -0.48 ).

From the results, it can therefore be stated that such simple yet robust cold climate specific changes could improve related water quality results significantly, and that these changes could be useful to other cold climate regions of the world.

\subsection{Model Validation for Water Quality Results in the Base Period}

Out of several parameters that control nutrients yield (also termed as export coefficient as it represents the nutrient generated per unit area per unit time (McFarland and Hauck, 2001) from sub-basins, the organic nitrogen and phosphorus enrichment ratios (ERORGN and ERORGP, Table 1) are found to be the most sensitive ones. Similarly, phosphorus up- take distribution parameters $\left(P_{-} U P D I S\right)$, phosphorus avail- able index $(P S P)$ and biological mixing efficiency $(B I O M I X)$ have been found to be the top five sensitive parameters. This is similar to the findings of other studies (e.g., Tiruneh, 2004).

As expected, both the (total) nitrogen $(T N)$ and phosphorus $(T P)$ yield from the agricultural areas are the highest. The average annual $T N$ yield (11.16 kgN/ha) from agricultural areas is comparable to literature values reported in similar cold climate watersheds. For instance, a value Nicholaichuk and Read (1978) reported yield rate of $10.00 \mathrm{kgN} / \mathrm{ha} / \mathrm{yr}$ in the Swift Current Watershed of Saskatchewan, Canada. Similarly, Dodd et al. (1992) reported a value of $9.80 \mathrm{kgN} / \mathrm{ha} / \mathrm{yr}$ in North Carolina, USA while MDEQ (2001) calculated the rate being 14.90 in Montana, USA. Similarly, the annual average TP yield from agricultural areas is $2.88 \mathrm{kgP} / \mathrm{ha} / \mathrm{yr}$, which is also comparable to the reported values in literature, such as 2.9 $\mathrm{kgP} / \mathrm{ha} / \mathrm{yr}$ reported by Nicholaichuk and Read (1978). As Spring Wheat and Barley are the major crops in the ARB, the TP yield is also comparable to the reported value of 2.96 $\mathrm{kgP} / \mathrm{ha} / \mathrm{yr}$ from the wheat fields in Oklahoma, USA (Olness et al., 1975). However, the average annual $T N$ yield rate of 0.94 $\mathrm{kgN} / \mathrm{ha} / \mathrm{yr}$ from the dominating land-use (forest) of the basin is found to be slightly lower than most of the reported values, e.g., $2.33 \mathrm{kgN} / \mathrm{ha} / \mathrm{yr}$ by Dodd et al. (1992) in North Carolina, USA, and $2.50 \mathrm{kgN} / \mathrm{ha} / \mathrm{yr}$ by MDEQ (2001) in Montana, USA. This could be due to a rather mild slope (Figure S6) in parts of the basin where the coverage forest land-use is the highest (Figure S5). As erosion potential in such flat areas is rather low, the organic nitrogen yield found in the sediments would be low. However, the annual $T P$ yield rate of $0.17 \mathrm{kgP} / \mathrm{ha}$ from the forest land-use is fairly comparable to the estimates in nearby watersheds-Baptiste Lake $(0.14 \mathrm{kgP} / \mathrm{ha} / \mathrm{yr}$, ) and Two Creek (0.12 kgP/ha/yr) (Alberta-Environment, 1982) of Alberta, Canada. The nutrients yield from other land-use types (pasture, rangeland, etc.) are also found to be consistent with literature values.

With reasonable estimates of nutrient runoff from the sub-basins, concentrations of five water quality components (stream water temperature - $T s$, dissolved oxygen - DO, carbonaceous biochemical oxygen demand $-c B O D$, total ni- trogen $-T N$ and phosphorus $-T P$ ) at 10 different stations (Figure 2) are calibrated.

Out of several parameters that affect in-stream water quality conversion (Table S8), two parameters that are directly related to the $\mathrm{cBOD}$ dynamics (cBOD settling rate $-R K 3$, and cBOD deoxygenation coefficient- $R K 1$, Table $\mathrm{S} 8$ ) are found to be most sensitive ones. This could be due to the fact that these parameters not only affect the $c B O D$ dynamics but also the $D O$ dynamics. Other sensitive parameters include sediment oxygen demand $(R K 4)$, re-aeration coefficient $(R K 2)$ and reaeration seasonality coefficient $(\psi)$. Out of four tem- perature related parameters (Table S8), the slope of inflection point $(\gamma)$ is found to be most sensitive, which is similar to the finding of Shrestha et al. (2013b).

Figure 5 shows the time series plot of simulated and observed $T s, c B O D, D O, T N$ and $T P$, with $95 \%$ predictive uncertainty bands at the Athabasca river $\mathrm{u} / \mathrm{s}$ of Fort McMurray during the calibration period. Table 4 summarizes the goodness of fit statistics and related qualitative rating of simulation results of each of the water quality variables at other stations. In general, the model is able to reproduce the trend of observations quite well, although some disparities also are evident.

As for $T s$, model results are consistent with qualitative ratings varying from "good" to "very good" at all stations (Table 4). The calculated p- and r-factors also reflect low uncertainty in model results ( $\mathrm{r}$-factor < 0.36). However, the uncertainty band could not encapsulate the majority of observations ( $\mathrm{p}$-factor $<0.56$ ). At the Athabasca river $\mathrm{u} / \mathrm{s}$ of Fort McMurray, the trend of observations has been represented quite well at both temperature extremes. From a management point of view, it is clear from the plot (Figure 5) that, at the Athabasca river $\mathrm{u} / \mathrm{s}$ of Fort McMurray, the $T s$ levels have never crossed the upper limit set for the Cyprinid waters (Table 3) but the upper limit set for the Salmonid waters has been crossed quite frequently in the summer months.

Similarly, for the $c B O D$ simulations, the goodness-of-fit statistics show only "satisfactory" accuracy of model simulations at all stations (Table 4). While the PBIAS indicated a 
Table 4. Goodness-of-fit Statistics of Water Quality Simulation Results with p- and r-statistics at 10 Selected Water Quality Monitoring Stations across the Athabasca River Basin (ARB)

\begin{tabular}{|c|c|c|c|c|c|c|c|c|}
\hline Variable & Monitoring Station Name and ID & Region & $\begin{array}{l}\text { No. of } \\
\text { Obs. }\end{array}$ & $\begin{array}{l}p- \\
\text { factor }\end{array}$ & $\begin{array}{l}r \text { - } \\
\text { factor }\end{array}$ & PBIAS & $N S E$ & $R S R$ \\
\hline \multirow{10}{*}{$\begin{array}{l}\text { Water } \\
\text { Temperature } \\
(T s)\end{array}$} & (AB07DD0010) & Boreal & 102 & 0.45 & 0.25 & $2.1(\mathrm{v})$ & $0.83(\mathrm{v})$ & $0.41(\mathrm{v})$ \\
\hline & (AB07DA0610) & Boreal & 102 & 0.38 & 0.18 & $1.9(\mathrm{v})$ & $0.79(\mathrm{v})$ & $0.46(\mathrm{v})$ \\
\hline & $(\mathrm{AB} 07 \mathrm{CC} 0030)$ & Boreal & 102 & 0.34 & 0.27 & $0.2(v)$ & $0.7(\mathrm{v})$ & $0.55(\mathrm{v})$ \\
\hline & (AB07BK0130) & Lesser Slave & 46 & 0.48 & 0.34 & $2(v)$ & $0.85(\mathrm{v})$ & $0.38(\mathrm{v})$ \\
\hline & (AB07BD0050) & Lesser Slave & 31 & 0.42 & 0.27 & $0.7(\mathrm{v})$ & $0.85(\mathrm{v})$ & $0.39(\mathrm{v})$ \\
\hline & (AB07BE0010) & Lesser Slave & 184 & 0.39 & 0.25 & $2.1(v)$ & $0.77(\mathrm{v})$ & $0.48(\mathrm{v})$ \\
\hline & (AB07AH0370) & Lesser Slave & 30 & 0.40 & 0.27 & $1.1(\mathrm{v})$ & $0.78(\mathrm{v})$ & $0.47(\mathrm{v})$ \\
\hline & (AB07AE0160) & Foothills & 57 & 0.35 & 0.31 & $1.9(\mathrm{v})$ & $0.73(\mathrm{v})$ & $0.52(\mathrm{v})$ \\
\hline & (AB07AD0160) & Foothills & 51 & 0.43 & 0.36 & $-2.5(v)$ & $0.71(\mathrm{v})$ & $0.54(\mathrm{v})$ \\
\hline & (AB07AD0360) & Headwater & 43 & 0.56 & 0.26 & $2.7(\mathrm{v})$ & $0.91(\mathrm{v})$ & $0.31(\mathrm{v})$ \\
\hline \multirow{10}{*}{$\begin{array}{l}\text { Dissolved } \\
\text { Oxygen }(D O)\end{array}$} & (AB07DD0010) & Boreal & 111 & 0.63 & 0.42 & $6(v)$ & $0.28(\mathrm{u})$ & $0.85(\mathrm{u})$ \\
\hline & (AB07DA0610) & Boreal & 101 & 0.42 & 0.32 & $25.8(\mathrm{~g})$ & $-1.1(\mathrm{u})$ & $1.44(\mathrm{u})$ \\
\hline & (AB07CC0030) & Boreal & 111 & 0.76 & 0.67 & $8.5(\mathrm{v})$ & $0.34(\mathrm{u})$ & $0.81(\mathrm{u})$ \\
\hline & (AB07BK0130) & Lesser Slave & 38 & 0.82 & 0.53 & $4.2(\mathrm{v})$ & $0.17(\mathrm{u})$ & $0.91(\mathrm{u})$ \\
\hline & (AB07BD0050) & Lesser Slave & 28 & 0.21 & 0.44 & $-4.2(v)$ & $0.18(\mathrm{u})$ & $0.9(\mathrm{u})$ \\
\hline & (AB07BE0010) & Lesser Slave & 189 & 0.66 & 0.84 & $12.4(\mathrm{v})$ & $-0.6(u)$ & $1.26(\mathrm{u})$ \\
\hline & (AB07AH0370) & Lesser Slave & 26 & 0.38 & 0.91 & $8.8(\mathrm{v})$ & $-2.4(\mathrm{u})$ & $1.84(\mathrm{u})$ \\
\hline & (AB07AE0160) & Foothills & 52 & 0.47 & 0.95 & $11.8(\mathrm{v})$ & $-3(\mathrm{u})$ & $1.99(\mathrm{u})$ \\
\hline & (AB07AD0160) & Foothills & 53 & 0.74 & 0.96 & $7.2(\mathrm{v})$ & $-0.9(\mathrm{u})$ & $1.38(\mathrm{u})$ \\
\hline & (AB07AD0360) & Headwater & 45 & 0.80 & 0.78 & $5.4(v)$ & $0(\mathrm{u})$ & $0.99(\mathrm{u})$ \\
\hline \multirow{10}{*}{$\begin{array}{l}\text { Total Nitrogen } \\
(T N)\end{array}$} & (AB07DD0010) & Boreal & 103 & 0.42 & 1.05 & $-18.7(v)$ & $-1(\mathrm{u})$ & $1.4(\mathrm{u})$ \\
\hline & (AB07DA0610) & Boreal & 60 & 0.32 & 1.22 & $4.4(v)$ & $-8.5(\mathrm{u})$ & $3.09(\mathrm{u})$ \\
\hline & (AB07CC0030) & Boreal & 103 & 0.35 & 0.82 & $-11.9(v)$ & $-1.6(\mathrm{u})$ & $1.62(\mathrm{u})$ \\
\hline & (AB07BK0130) & Lesser Slave & 45 & 0.60 & 0.69 & $1.7(\mathrm{v})$ & $-0.2(\mathrm{u})$ & $1.09(\mathrm{u})$ \\
\hline & (AB07BD0050) & Lesser Slave & 34 & 0.58 & 0.55 & $-7.7(v)$ & $0.04(\mathrm{u})$ & $0.98(\mathrm{u})$ \\
\hline & (AB07BE0010) & Lesser Slave & 190 & 0.38 & 0.56 & $-3(v)$ & $-0.5(\mathrm{u})$ & $1.22(\mathrm{u})$ \\
\hline & (AB07AH0370) & Lesser Slave & 32 & 0.25 & 0.28 & $4.1(\mathrm{v})$ & $-0.2(\mathrm{u})$ & $1.08(\mathrm{u})$ \\
\hline & (AB07AE0160) & Foothills & 58 & 0.52 & 0.75 & $-5.6(v)$ & $0.23(\mathrm{u})$ & $0.88(\mathrm{u})$ \\
\hline & (AB07AD0160) & Foothills & 50 & 0.27 & 0.36 & $-33.1(\mathrm{~g})$ & $-0.1(\mathrm{u})$ & $1.07(\mathrm{u})$ \\
\hline & (AB07AD0360) & Headwater & 46 & 0.37 & 0.63 & $-7.5(v)$ & $-0.6(u)$ & $1.25(\mathrm{u})$ \\
\hline \multirow{10}{*}{$\begin{array}{l}\text { Total } \\
\text { Phosphorus } \\
(T P)\end{array}$} & (AB07DD0010) & Boreal & 103 & 0.36 & 0.46 & $-24.3(v)$ & $-0.3(\mathrm{u})$ & $1.15(\mathrm{u})$ \\
\hline & (AB07DA0610) & Boreal & 61 & 0.16 & 0.56 & $-17.8(v)$ & $-2.2(\mathrm{u})$ & $1.79(\mathrm{u})$ \\
\hline & (AB07CC0030) & Boreal & 103 & 0.21 & 0.55 & $-0.8(v)$ & $-1.3(\mathrm{u})$ & $1.52(\mathrm{u})$ \\
\hline & (AB07BK0130) & Lesser Slave & 45 & 0.78 & 1.23 & $3.9(\mathrm{v})$ & $0.21(\mathrm{u})$ & $0.89(\mathrm{u})$ \\
\hline & (AB07BD0050) & Lesser Slave & 34 & 0.12 & 0.40 & $65(\mathrm{~s})$ & $-2.1(\mathrm{u})$ & $1.75(\mathrm{u})$ \\
\hline & (AB07BE0010) & Lesser Slave & 190 & 0.22 & 0.30 & $-10.8(v)$ & $-0.4(\mathrm{u})$ & $1.19(\mathrm{u})$ \\
\hline & (AB07AH0370) & Lesser Slave & 31 & 0.16 & 0.17 & $27.7(\mathrm{~g})$ & $-0.3(\mathrm{u})$ & $1.15(\mathrm{u})$ \\
\hline & (AB07AE0160) & Foothills & 58 & 0.36 & 0.23 & $-4.1(v)$ & $-0.1(\mathrm{u})$ & $1.03(\mathrm{u})$ \\
\hline & (AB07AD0160) & Foothills & 50 & 0.48 & 0.26 & $-31.5(\mathrm{~g})$ & $-0.1(\mathrm{u})$ & $1.06(\mathrm{u})$ \\
\hline & (AB07AD0360) & Headwater & 46 & 0.27 & 0.49 & $-13.7(v)$ & $-0.1(\mathrm{u})$ & $1.04(\mathrm{u})$ \\
\hline \multirow{8}{*}{$\begin{array}{l}\text { Carbonaced } \\
\text { Biological } \\
\text { Oxygen } \\
\text { Demand } \\
\text { (cBOD) }\end{array}$} & (AB07DD0010) & Boreal & 17 & 0.47 & 1.70 & $-9.5(\mathrm{v})$ & $-1.5(\mathrm{u})$ & $1.57(\mathrm{u})$ \\
\hline & (AB07DA0610) & Boreal & 39 & 0.26 & 0.91 & $9(\mathrm{v})$ & $-1.6(\mathrm{u})$ & 1.61(u) \\
\hline & $(\mathrm{AB} 07 \mathrm{CC} 0030)$ & Boreal & 29 & 0.52 & 1.61 & $6.8(v)$ & $-1(\mathrm{u})$ & $1.41(\mathrm{u})$ \\
\hline & (AB07BK0130) & Lesser Slave & 39 & 0.19 & 0.62 & $-9.5(v)$ & $-0.1(\mathrm{u})$ & $1.05(\mathrm{u})$ \\
\hline & (AB07BD0050) & Lesser Slave & 21 & 0.45 & 1.16 & $-16.4(v)$ & $0.22(\mathrm{u})$ & $0.88(\mathrm{u})$ \\
\hline & (AB07BE0010) & Lesser Slave & 20 & 0.49 & 0.93 & $-24.9(v)$ & $-0.2(\mathrm{u})$ & $1.08(\mathrm{u})$ \\
\hline & (AB07AH0370) & Lesser Slave & 19 & 0.32 & 0.90 & $0(\mathrm{v})$ & $-0.3(\mathrm{u})$ & $1.13(\mathrm{u})$ \\
\hline & (AB07AE0160) & Foothills & 23 & 0.17 & 0.68 & $1.6(\mathrm{v})$ & $-0.2(\mathrm{u})$ & $1.09(\mathrm{u})$ \\
\hline
\end{tabular}

Qualitative Ratings as per Moriasi et al. (2007, 2015), see Table 3.

$\mathrm{v}=$ very good $\mathrm{g}=$ good $\mathrm{s}=$ satisfactory $; \mathrm{u}=$ unsatisfactory. 
"very good" accuracy, negative NSE and a high value of RSR indicated "unsatisfactory" accuracy of model simulations. This indicates that the model tends to reproduce the long-term average $C B O D$ dynamics quite well but it fails to reproduce $c B O D$ dynamics in a shorter time (daily) basis. However, the fact that very limited numbers of $c B O D$ observations $(<40$ at
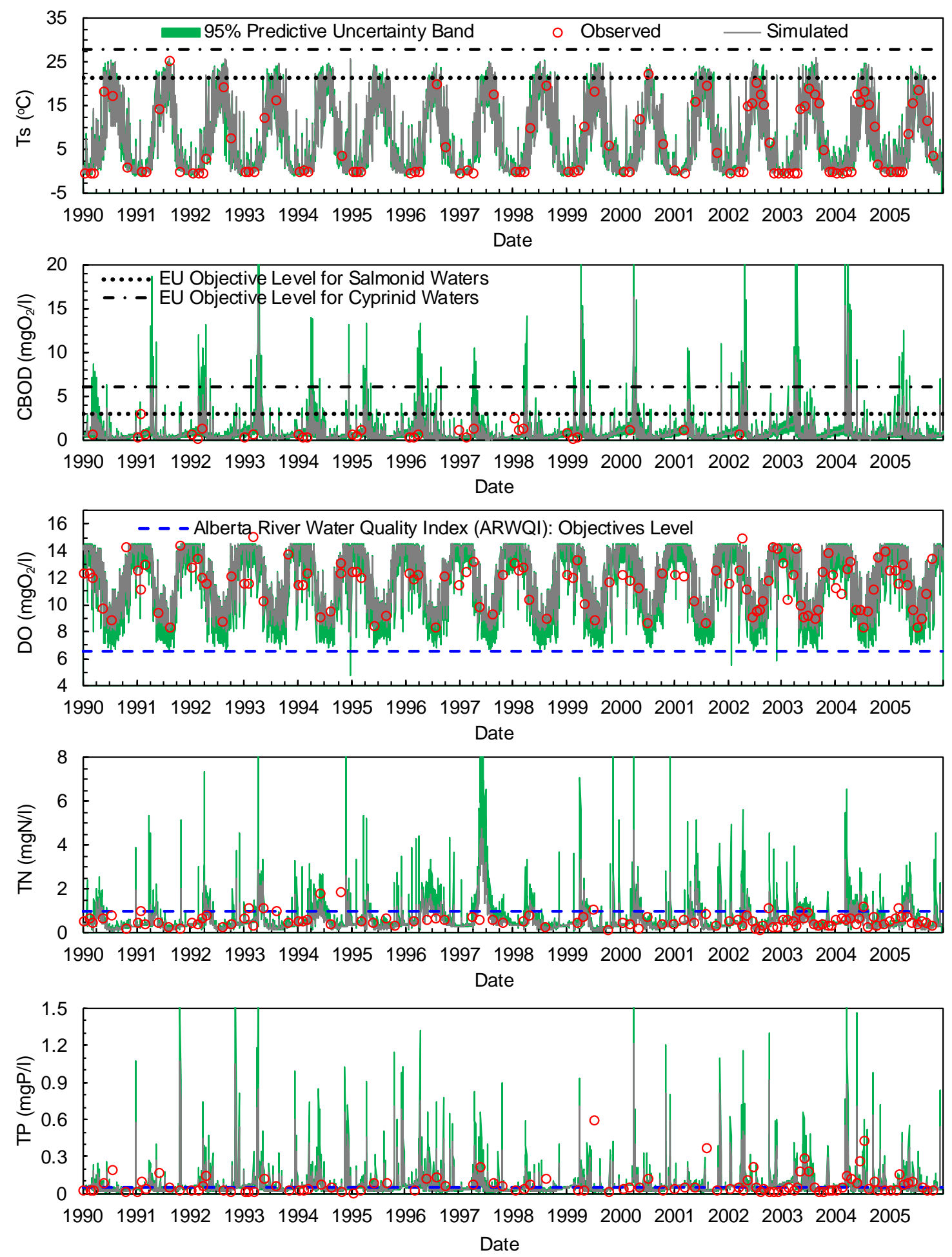

Figure 5. Time series plots of observed and simulated daily water quality variables (stream water temperature - $T s$, carbonaceous biochemical oxygen demand- $c B O D$, dissolved oxygen- $D O$, total nitrogen- $T N$, and total phosphorus- $T P$ ) at Athabasca river u/s Fort McMurray (\#AB07CC0030). Also shown is the $95 \%$ total predictive uncertainty bands on the model results. 
all stations in the calibration period, Table 4) are available, indicates that these statistics should be used with caution. The fact that there are no $c B O D$ measurements that are greater than $3 \mathrm{mgO}_{2} / \mathrm{L}$ (Figure 5) at the Athabasca river u/s of Fort McMurray also shows our inability to validate the model results in more extreme events. High $c B O D$ (up to $15 \mathrm{mgO}_{2} / \mathrm{L}$, Figure 5) concentrations are indeed expected during spring freshet and storm events. From a management point of view, it is clear from the plot (Figure 5) that at the Athabasca river $\mathrm{u} / \mathrm{s}$ of Fort McMurray, the ecological status of the river is good during low flow conditions as the $c B O D$ concentrations are well below the limits set for both Cyprinid and Salmonid waters. However, both limits have been frequently crossed during storm events and in the spring freshet.

Concerning the $D O$ simulations, a slightly improved accuracy has been observed across all the stations than that calculated for the $c B O D$ simulations, albeit due to a higher number of observations (Table 4). Slightly better values of goodness-of-fit statistics have been observed at stations located in the downstream section of the basin. For all stations, reasonable values of $\mathrm{r}$-factor $(<1$ ), and p-factor (up to 0.82 ) indicate higher levels of confidence on the $D O$ simulations. At the Athabasca river u/s of Fort McMurray, the model has reproduced the dynamics of $D O$ in both extremes (summer and winter), but there is a general tendency of overestimation during winter months (Figure 5) in low flows periods and extensive ice cover even after these improvements due to the introduction of seasonality in air-water oxygen transfer (Equation 3). This can be related to the conceptual deficiency of the QUAL2E principles that the SWAT adopts for in-stream water quality conversion. As highlighted by Reichert et al. (2001), the QUAL2E formulation has not considered various oxygen consuming processes such as the growth and respiration of first and second stage nitrifiers, consumers and heterotrophs. In relation to the cold climate regions, perhaps one of the more important factors could be the presence of seasonality in the sediment oxygen demand (Table S8, process 4) as confirmed by several field studies, e.g. (Northern River Basins and Monenco, 1993). In contrast, the QUAL2E formulation adopts a constant rate (RK4, Table S8, process 4). In reality, a gradual build-up in sediment oxyge demand is expected in rivers with extensive ice cover in winter months due to a continuous release of biodegradable biomass and nutrients into the river, resulting in an increase of benthic biomass and activities of nitrifiers, consumers and heterotrophs. During the spring freshet period, increasing streamflow would erode the accumulated benthic biomass and the sediment oxygen demand would drop, further indicating the presence of seasonality in sediment oxygen demand. A study of Casey (1990) indeed confirmed this phenomena using several in-situ measurements at several locations of the Athabasca river. Accordingly, some studies have considered the seasonality in the sediment oxygen demand and are able to get slightly better results in simulating the $D O$ dynamics (Pietroniro et al., 1998; Akomeah and Lindenschmidt, 2017; Terry et al., 2017). This issue needs further investigation. From a management point of view, the $D O$ levels at the Athabasca river $\mathrm{u} / \mathrm{s}$ of Fort
McMurray have, for the majority of periods, remained above $6.5 \mathrm{mgO}_{2} / 1$, the objective level set by AEP (2017). The DO levels have occasionally dropped below the objective level at storm conditions or during spring freshet, which are often associated with high $c B O D$ loadings from upland sub-basins.

As for the $T N$ and $T P$ simulations, the overall accuracy of the simulation results at all stations is just 'satisfactory' (Table 4). Low or negative NSE values indicate that the model failed to capture the diurnal nutrients dynamics. It should, however, be noted that the observations are instantaneous measurements but samples have been collected from a point in the water column. Owing to the width and depth of the river, especially in the downstream sections, notable variations in the nutrient concentrations across the river width and depth are expected. Hence, such direct comparison (instantaneous observations versus daily simulations) are expected to result in low NSE values as the statistics are sensitive to the squared of residuals of individual pairs. However, the qualitative rating corresponding the PBIAS, which compares long term averaged values for the most of the cases, is 'very good'. Similarly, reasonable $\mathrm{p}$ - and r-stat indicate higher confidence in model results with a low uncertainty (Table 4). At the Athabasca river $\mathrm{u} / \mathrm{s}$ of Fort McMurray, the model results tend to capture the trend of observed $T N$ and $T P$ quite well, albeit with some discrepancies. As nutrient concentrations in the river reaches are primarily determined by the nutrients loading from surface runoff (Equation S1-S4), frequent peaks are evident during spring freshet periods and in storm events. From a management point of view, both the $T N$ and $T P$ concentrations exceed the objectives level set by AEP (2017) quite frequently. In general, the concentrations remained below the level only during low flow periods.

\subsection{Climate Change Impacts}

The future climate data clearly shows that the ARB will be warmer and wetter, relative to the base period. The trend is especially more severe in the late-century period and for the higher emission scenario. Basin wide annual average values suggest that the ARB is projected to be warmer by $2 \sim 3{ }^{\circ} \mathrm{C}$ and $2.5 \sim 5.4{ }^{\circ} \mathrm{C}$ in the mid- and late-century periods, respectively, relative to the base period. Similarly, the ARB is projected to receive higher precipitation by 27 and $37 \%$, respectively for mid- and late-century periods, relative to the base period. While the projected increases in temperature are consistent with the reported values in the literature (Toth et al., 2006; Golder-Associates, 2009; Kerkhoven and Gan, 2011; Leong and Donner, 2015; Eum et al., 2017), the increases in precipitation are slightly higher than that reported in these studies. While analyzing the changes in seasonal and regional scales, it is clear that there exists a marked variability within the basin (Table S5).

\subsubsection{Nutrients Runoff from Sub-basins}

The marked spatial variability in the annual average nutrients yield (total nitrogen - TN, Figure 6 and phosphorus $T P$, Figure 7) during the base period have reflected variability 
in the land-use pattern of the basin. Regional average seasonal and annual yields (Table 5) have also confirmed this heterogeneity. In general, the regions having higher proportions of agriculture area have resulted in a higher nutrients yield (Table 6) mainly due to fertilizer applications associated with the agricultural activities. Further, due to nutrients' association with sediment, some sub-basins of the headwater region have also contributed substantially as they are the source areas of sediments (Table S5).
In future, despite a significant projected increase in summer sediment yield from the headwater and foothill regions (Table S5), the nutrients yield in the summer season, on average, are projected to decrease (up to $60 \%$ on $T N$ and up to $73 \%$ on $T P$ in the headwater region). The expected increment in nutrients yield due to their association with sediments might have been over-compensated by the projected increase in water yield (Table S5). It implies that the dilution effect might exert greater control in $T N$ and $T P$ yield in these regions of

Table 5. Percentage Change in Seasonal and Annual Total Nitrogen (kgN/ha) and Total Phosphorus (kgP/ha) Yield from Different Regions of the Athabasca River Basin (ARB) in Mid- (2021-2060) and Late-century (2061-2100) Periods, and for Two Emission Scenarios (RCP 4.5 and 8.5), Relative to Base Period (1983-2013)

\begin{tabular}{|c|c|c|c|c|c|c|c|c|c|c|c|c|c|}
\hline \multirow[t]{2}{*}{ Variable } & \multirow{2}{*}{$\begin{array}{l}\text { Region/Season } \\
\text { Period }\end{array}$} & \multicolumn{8}{|c|}{ Headwaters } & \multicolumn{4}{|c|}{ Foothills } \\
\hline & & DJF & MAM & & JJA & & & Ant & & DJF & MAM & & SON \\
\hline \multirow{5}{*}{$\begin{array}{l}\text { Total } \\
\text { Nitrogen Yield } \\
(\mathrm{kgN} / \mathrm{ha})\end{array}$} & $\begin{array}{l}\text { Base Period } \\
(1983-2013)\end{array}$ & 0.015 & 0.177 & & 0.215 & \multicolumn{2}{|c|}{0.073} & \multicolumn{2}{|c|}{0.479} & 0.018 & 0.109 & 0.225 & 0.059 \\
\hline & $\begin{array}{l}\text { RCP 4.5 } \\
(2021-2061)\end{array}$ & $-99 \%$ & $-76 \%$ & & $54 \%$ & \multicolumn{2}{|c|}{$-44 \%$} & \multicolumn{2}{|c|}{$-14 \%$} & $3 \%$ & $50 \%$ & $-10 \%$ & $8 \%$ \\
\hline & $\begin{array}{l}\text { RCP } 4.5 \\
(2061-2100)\end{array}$ & $-98 \%$ & $-85 \%$ & & $-53 \%$ & \multicolumn{2}{|c|}{$-72 \%$} & \multicolumn{2}{|c|}{$-69 \%$} & $38 \%$ & $51 \%$ & $-2 \%$ & $35 \%$ \\
\hline & $\begin{array}{l}\text { RCP 8.5 } \\
(2021-2061)\end{array}$ & $-99 \%$ & $-76 \%$ & & $0 \%$ & \multicolumn{2}{|c|}{$-49 \%$} & \multicolumn{2}{|c|}{$-39 \%$} & $5 \%$ & $42 \%$ & & $8 \%$ \\
\hline & $\begin{array}{l}\text { RCP 8.5 } \\
(2061-2100)\end{array}$ & $-97 \%$ & $-65 \%$ & & $-54 \%$ & & & -60 & & $62 \%$ & $84 \%$ & & $44 \%$ \\
\hline $\begin{array}{l}\text { Total } \\
\text { Phosphorus Yield }\end{array}$ & $\begin{array}{l}\text { Base Period } \\
(1983-2013)\end{array}$ & 0.004 & 0.187 & & 0.402 & & & 0.6 & & 0.003 & 0.018 & & 0.002 \\
\hline (kgP/ha) & $\begin{array}{l}\text { RCP 4.5 } \\
(2021-2061)\end{array}$ & $-100 \%$ & $-77 \%$ & & $15 \%$ & & & -15 & & $-44 \%$ & $-28 \%$ & & $-6 \%$ \\
\hline & $\begin{array}{l}\text { RCP 4.5 } \\
(2061-2100)\end{array}$ & $-100 \%$ & $-86 \%$ & & $-67 \%$ & & & -73 & & $40 \%$ & $-23 \%$ & & $44 \%$ \\
\hline & $\begin{array}{l}\text { RCP 8.5 } \\
(2021-2061)\end{array}$ & $-99 \%$ & $-74 \%$ & & $13 \%$ & & & -16 & & $-16 \%$ & $-27 \%$ & & $4 \%$ \\
\hline & $\begin{array}{l}\text { RCP 8.5 } \\
(2061-2100)\end{array}$ & $-99 \%$ & $-79 \%$ & & $-72 \%$ & & & -73 & & $91 \%$ & $-9 \%$ & & $67 \%$ \\
\hline Variable & Region/Season & Foothill & & Prairie & & & & & & & & Lesse & \\
\hline & Period & Annual & & DJF & & MAM & & & SOI & & Annual & DJF & MAM \\
\hline $\begin{array}{l}\text { Total } \\
\text { Nitrogen Yield }\end{array}$ & $\begin{array}{l}\text { Base Period } \\
(1983-2013)\end{array}$ & 0.412 & & 0.006 & & 0.325 & & 097 & 0.03 & & 0.460 & 0.090 & 0.982 \\
\hline$(\mathrm{kgN} / \mathrm{ha})$ & $\begin{array}{l}\text { RCP 4.5 } \\
(2021-2061)\end{array}$ & $9 \%$ & & $133 \%$ & & $-5 \%$ & & $9 \%$ & $11 \%$ & & $26 \%$ & $-52 \%$ & $70 \%$ \\
\hline & $\begin{array}{l}\text { RCP 4.5 } \\
(2061-2100)\end{array}$ & $19 \%$ & & $289 \%$ & & $1 \%$ & & $\%$ & $48 \%$ & & $26 \%$ & $-28 \%$ & $80 \%$ \\
\hline & $\begin{array}{l}\text { RCP 8.5 } \\
(2021-2061)\end{array}$ & $8 \%$ & & $57 \%$ & & $-7 \%$ & & $7 \%$ & $20 \%$ & & $20 \%$ & $-44 \%$ & $97 \%$ \\
\hline & $\begin{array}{l}\text { RCP 8.5 } \\
(2061-2100)\end{array}$ & $19 \%$ & & $609 \%$ & & $16 \%$ & & $\%$ & 121 & & $32 \%$ & $52 \%$ & $106 \%$ \\
\hline $\begin{array}{l}\text { Total } \\
\text { Phosphorus Yield }\end{array}$ & $\begin{array}{l}\text { Base Period } \\
(1983-2013)\end{array}$ & 0.035 & & 0.038 & & 0.514 & & 136 & 0.04 & & 0.731 & 0.022 & 0.136 \\
\hline$(\mathrm{kgP} / \mathrm{ha})$ & $\begin{array}{l}\text { RCP 4.5 } \\
(2021-2061)\end{array}$ & $-24 \%$ & & $15 \%$ & & $6 \%$ & & $3 \%$ & $-6 \%$ & & $54 \%$ & $-34 \%$ & $91 \%$ \\
\hline & $\begin{array}{l}\text { RCP 4.5 } \\
(2061-2100)\end{array}$ & $-3 \%$ & & $84 \%$ & & $15 \%$ & & $8 \%$ & $92 \%$ & & $58 \%$ & $5 \%$ & $138 \%$ \\
\hline & $\begin{array}{l}\text { RCP 8.5 } \\
(2021-2061)\end{array}$ & $-15 \%$ & & $-12 \%$ & & $2 \%$ & & $8 \%$ & $20 \%$ & & $39 \%$ & $-29 \%$ & $130 \%$ \\
\hline & $\begin{array}{l}\text { RCP 8.5 } \\
\text { (2061-2100) }\end{array}$ & $1 \%$ & & $341 \%$ & & $33 \%$ & & $\%$ & 196 & & $67 \%$ & $210 \%$ & $166 \%$ \\
\hline
\end{tabular}


Continued

\begin{tabular}{|c|c|c|c|c|c|c|c|c|c|}
\hline \multirow[t]{2}{*}{ Variable } & \multirow{2}{*}{$\begin{array}{l}\text { Region/Season } \\
\text { Period } \\
\end{array}$} & \multicolumn{3}{|c|}{ Lesser Slave } & \multicolumn{5}{|l|}{ Boreal } \\
\hline & & JJA & SON & Annual & DJF & MAM & JJA & SON & Annual \\
\hline \multirow{5}{*}{$\begin{array}{l}\text { Total } \\
\text { Nitrogen Yield } \\
(\mathrm{kgN} / \mathrm{ha})\end{array}$} & $\begin{array}{l}\text { Base Period } \\
(1983-2013)\end{array}$ & 1.573 & 0.220 & 2.866 & 0.028 & 0.344 & 0.581 & 0.103 & 1.055 \\
\hline & $\begin{array}{l}\text { RCP 4.5 } \\
(2021-2061)\end{array}$ & $10 \%$ & $-13 \%$ & $27 \%$ & $110 \%$ & $103 \%$ & $159 \%$ & $174 \%$ & $141 \%$ \\
\hline & $\begin{array}{l}\text { RCP 4.5 } \\
(2061-2100)\end{array}$ & $-29 \%$ & $14 \%$ & $12 \%$ & $147 \%$ & $211 \%$ & $154 \%$ & $212 \%$ & $178 \%$ \\
\hline & $\begin{array}{l}\text { RCP 8.5 } \\
(2021-2061)\end{array}$ & $9 \%$ & $-4 \%$ & $37 \%$ & $109 \%$ & $142 \%$ & $160 \%$ & $146 \%$ & $151 \%$ \\
\hline & $\begin{array}{l}\text { RCP 8.5 } \\
(2061-2100)\end{array}$ & $-34 \%$ & $34 \%$ & $22 \%$ & $213 \%$ & $211 \%$ & $115 \%$ & $168 \%$ & $154 \%$ \\
\hline \multirow{5}{*}{$\begin{array}{l}\text { Total } \\
\text { Phosphorus } \\
\text { Yield } \\
\text { (kgP/ha) }\end{array}$} & $\begin{array}{l}\text { Base Period } \\
(1983-2013)\end{array}$ & 0.241 & 0.058 & 0.458 & 0.004 & 0.038 & 0.052 & 0.009 & 0.102 \\
\hline & $\begin{array}{l}\text { RCP 4.5 } \\
(2021-2061)\end{array}$ & $30 \%$ & $-16 \%$ & $39 \%$ & $65 \%$ & $163 \%$ & $212 \%$ & $177 \%$ & $185 \%$ \\
\hline & $\begin{array}{l}\text { RCP 4.5 } \\
(2061-2100)\end{array}$ & $-6 \%$ & $19 \%$ & $41 \%$ & $150 \%$ & $224 \%$ & $173 \%$ & $225 \%$ & $195 \%$ \\
\hline & $\begin{array}{l}\text { RCP 8.5 } \\
(2021-2061)\end{array}$ & $26 \%$ & $-2 \%$ & $51 \%$ & $111 \%$ & $251 \%$ & $183 \%$ & $110 \%$ & $199 \%$ \\
\hline & $\begin{array}{l}\text { RCP 8.5 } \\
(2061-2100)\end{array}$ & $-22 \%$ & $45 \%$ & $54 \%$ & $281 \%$ & $317 \%$ & $183 \%$ & $263 \%$ & $243 \%$ \\
\hline
\end{tabular}

the basin. It is also supported by the fact that there are limited fluctuations in the projected biomass yield in these regions (Table S5), thus limiting the addition of plant residue on fresh pools of organic nutrients. Even the significant changes in biomass yield due to favorable or non-favorable water and temperature stress (Table S5) would have little ef- fect on the dynamics of the nutrient yield as the parameters, such as the residue decomposition coefficient (RSDCO, Table 1) rate factor for humus mineralization of active organic nutrients $(C M N$, Table 1) are not very sensitive.

At the prairie region, where the majority of agricultural activities exist (Figure S3), significant projected increases in summer sediment yield have been reflected in the increases in $T N$ (up to $129 \%$ ) and TP (up to $263 \%$ ) yield despite projected increases in water yield (Table S5) in the summer season. Higher sediment associated organic nutrients runoff could be the main cause of this increment. At the same time, due to projected increases in plant biomass as a result of decreased temperature stress (Table S5), a higher amount of plant residue would contribute to the fresh pool of organic nutrients. Further, a higher rate of residual decay as a result of projected increases (up to $8.9{ }^{\circ} \mathrm{C}$, Table S5) in summer temperature would add more organic nutrients in to the active pool.

A similar pattern is also observed in the Lesser Slave region. However, the changes in this region are not as significant as those observed in the prairie region. At the boreal plain region, which has the forest as the major land-use (Figure S5) and has rather flat topography (Figure S6), significant increases in $T N$ and $T P$ yield during all seasons have been observed (Table 5). During summer and spring seasons, the increments can be mainly associated with the significant increases in sediment yield. However, an increment of the same magnitude during the winter and autumn seasons, in which there are no sediment yield from sub-basins (Table S5), could be attributed to an increased proportion of soluble forms of nutrients as the water yield (surface, lateral and groundwater) is projected to increase significantly (> $100 \%$ during these seasons, Table S5). Further, an increased proportion of organic nutrients in the fresh and active pools due to expected increases in plant biomass might also have contributed. Moreover, the mineralization process (conversion of organic nutrient from fresh and active pools to mineral forms) would be enhanced due to projected increases in temperature as all the processes that take place in the top soil layer (mineralization, decomposition and immobilization) can't occur if soil temperature is less than $0^{\circ} \mathrm{C}$ (Neitsch et al., 2011).

The changes in $T N$ and $T P$ yield in different land-use types (Table 6) of the ARB shows that the mean annual yield would increase in all land-use types. In the agricultural areas the highest $T N$ and $T P$ contributor in the base period, the increments are projected to be up by 48 and 69\%, respectively. The higher increments are found to be more for the midcentury period of both scenarios than for the end-century period. It should be noted that greater increases in the sediment yield (Table S6) as a result of more intense rainfall events in the end-century period, are projected in the endcentury period from the agricultural areas. This implies that expected increases in the sediment associated nutrients got diluted due to higher water yield, consequently leading to lower nutrients yield in the end-century period. However, in the forest, the dominating land-use type in the basin, the projected increases in $T N$ yield (Table 6) have closely followed the trend of the sediment yield changes (Table S6) but for the $T P$, the case is just the opposite. In a wetter and warmer future 
(a) Base Period

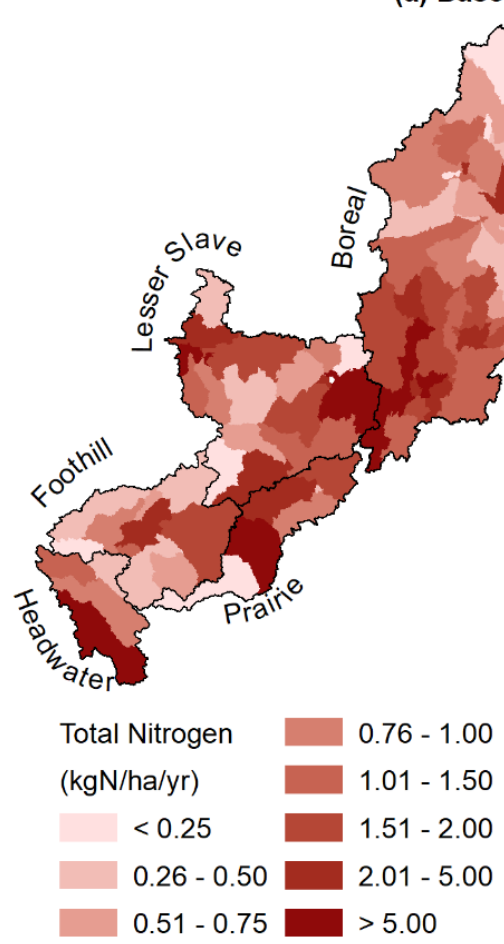

(b) Future Periods
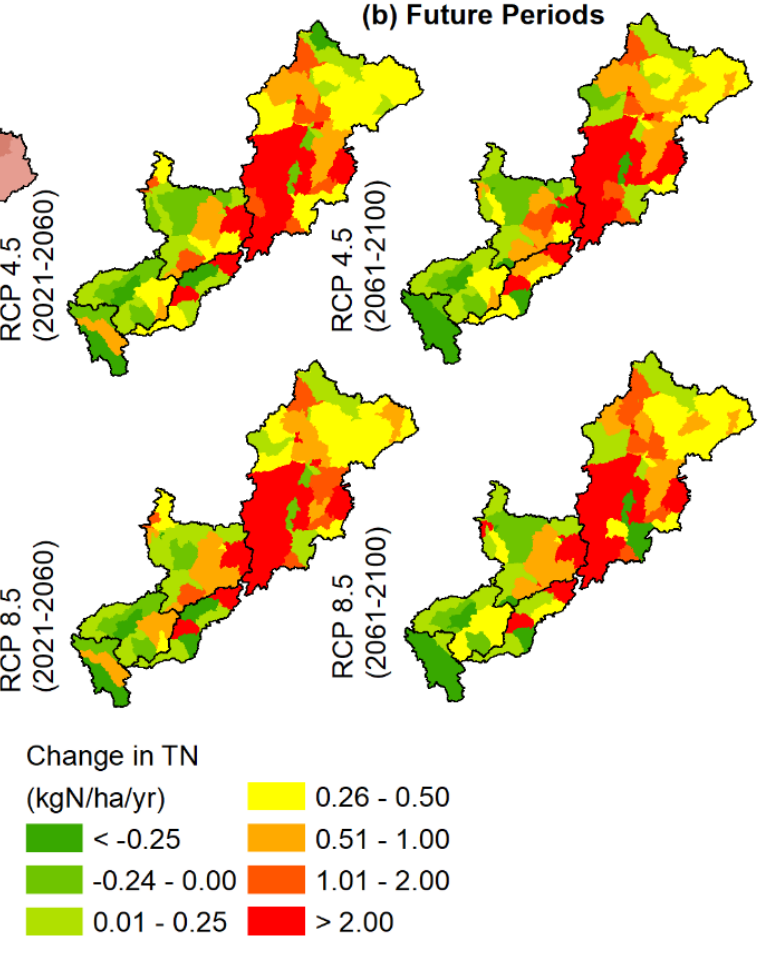

Figure 6. (a) Annual average total nitrogen $(T N)$ yield from sub-basins of Athabasca River Basin (ARB) in base period; (b) absolute changes in the TN yield in two emission scenarios in Mid- and Late-century periods, relative to base period (1983 2013).

(a) Base Period

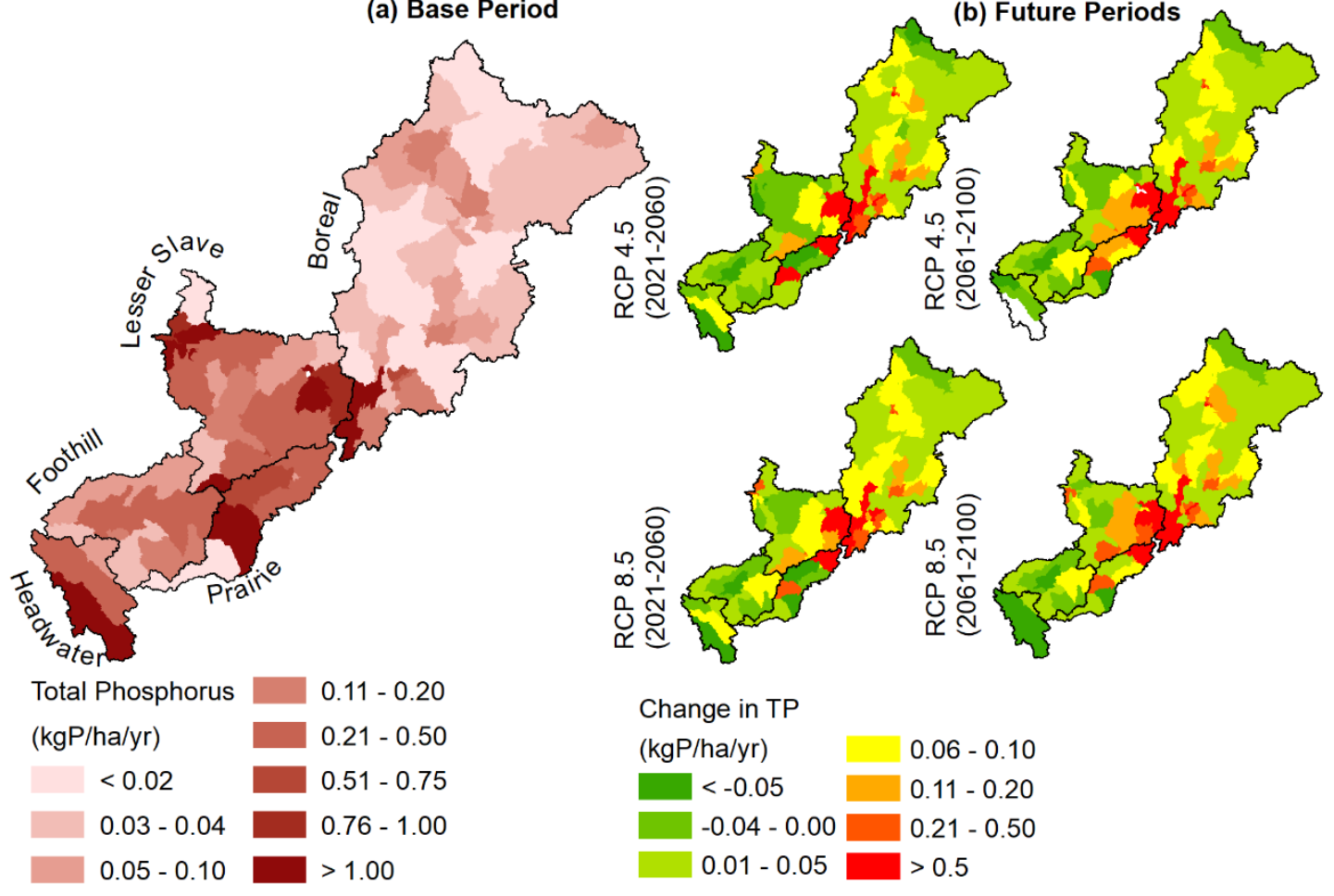

Figure 7. (a) Annual average total phosphorus (TP) yield from sub-basins of Athabasca River Basin (ARB) in base period; (b) absolute changes in the TP yield in two emission scenarios in Mid- and Late-century periods, relative to base period (1983 2013). 
Table 6. Percentage Changes in Annual Total Nitrogen ( $\mathrm{kgN} / \mathrm{ha}$ ) and Total Phosphorus $(\mathrm{kgP} / \mathrm{ha})$ Yield from Different Landuse Types of the Athabasca River Basin (ARB) in Mid- (2021-2060) and Late-century (2061-2100) Periods, and for Two Emission Scenarios (RCP 4.5 and 8.5), Relative to Base Period (1983-2013).

\begin{tabular}{lllllll}
\hline Nutrients & Land-use & $\begin{array}{l}\text { Base Period } \\
(1983 \sim 2013)\end{array}$ & $\begin{array}{l}\text { RCP 4.5 } \\
(2021 \sim 2060)\end{array}$ & $\begin{array}{l}\text { RCP 4.5 } \\
(2061 \sim 2100)\end{array}$ & $\begin{array}{l}\text { RCP 8.5 } \\
(2021 \sim 2060)\end{array}$ & $\begin{array}{l}\text { RCP 8.5 } \\
(2061 \sim 2100)\end{array}$ \\
\hline Total & Forest & 0.94 & $1.62(+73 \%)$ & $1.77(+90 \%)$ & $1.67(+78 \%)$ & $1.68(+80 \%)$ \\
Nitrogen & Agriculture & 11.16 & $15.2(+36 \%)$ & $12.75(+14 \%)$ & $16.52(+48 \%)$ & $13.69(+23 \%)$ \\
$(\mathrm{kgN} / \mathrm{ha})$ & Rangeland & 1.35 & $2.10(+56 \%$ & $2.15(+60 \%)$ & $2.15(+60 \%)$ & $2.65(+96 \%)$ \\
& Pasture & 0.70 & $1.02(+47 \%)$ & $1.25(+80 \%)$ & $1.06(+52 \%)$ & $1.62(+132 \%)$ \\
Total & Forest & 0.17 & $0.22(+30 \%)$ & $0.15(-10 \%)$ & $0.23(+32 \%)$ & $0.16(-6 \%)$ \\
Phosphorus & Agriculture & 2.88 & $4.58(+59 \%)$ & $4.02(+39 \%)$ & $4.89(+69 \%)$ & $4.41(+53 \%)$ \\
kgP/ha) & Rangeland & 1.74 & $3.01(+75 \%)$ & $2.93(+69 \%)$ & $3.26(+88 \%)$ & $3.00(+73 \%)$ \\
& Pasture & 0.48 & $1.53(+219 \%)$ & $1.06(+121 \%)$ & $1.29(+169 \%)$ & $1.74(+263 \%)$ \\
\hline
\end{tabular}

climate, plant growth would be more rapid, which might lower the runoff coefficient (Kerkhoven and Gan, 2011) allowing for higher infiltration and consequently reducing surface runoff. While decreased surface runoff decreases sediment yield, thereby decreasing nutrients enriched with the sediments, a higher nitrate contribution from lateral and ground water flows might be responsible for the projected increases in $T N$ yield. However, reduced surface runoff would lead to decreased phosphorus diffusion (Equation S4) which might be responsible for the decreases in $T P$ yield.

\subsubsection{Water Quality Concentrations at River Reaches}

Marked spatial variability in future nutrients yield from sub-basins (Figures 6 and 7) and significant spatial and temporal variability of temperature, water and sediment yield (Table S5) have been reflected in the future concentrations of different water quality variables. Table S7 shows the future changes of the concentrations of these variables at 10 selected stations across the basin. In general, $T s$ tend to increase (up to $6.3{ }^{\circ} \mathrm{C}$ ) in future, thereby reducing $D O$ concentrations (up to $-13 \%$ ) albeit driven by higher degradation of $c B O D$ due to elevated temperatures. Consequently, $c B O D$ concentrations tend to decrease but marked spatial and temporal variability $(+39$ to $-68 \%$ ) is evident. Similarly, $T N$ and $T P$ concentrations showed even higher variability (94 to $-52 \%$ for $T N$ and 47 to $-57 \%$ for $T P$ ). For clarity, we endeavored to present the projected changes for a specific station (Athabasca River u/s Fort McMurray, Figure 8) in detail.

At the Athabasca River u/s Fort McMurray, the $T s$, on average tend to increase for both emission scenarios and for both future periods (Figure 8a). The increments are more severe $\left(>6{ }^{\circ} \mathrm{C}\right)$ in the end-century period and for the higher emission scenario. From a management point of view, even at the worst conditions, the limit set for Cyprinid waters $\left(28^{\circ} \mathrm{C}\right.$, Table 3) has never been crossed, however, the limit of the Salmonid waters $\left(21.5^{\circ} \mathrm{C}\right.$, Table 3$)$ has been crossed in the summer months. It should be noted that these limits have not been crossed in the base period. Moreover, the increases on $T s$, a physical change, can force changes in other chemical properties of water (e.g., reduced $D O$ ). Further, the associated biological changes might include forced migration of coldwater species due to stress caused by higher Ts (ETCW, 2010).

The $c B O D$ dynamics (Figure $8 \mathrm{~b}$ ) at the Athabasca River $\mathrm{u} / \mathrm{s}$ Fort McMurray have showed that the monthly averaged concentrations generally tend to decrease even though the sediment yield is projected to increase (Table S5). While increased sediment yield would increase $c B O D$ in surface runoff due to higher organic carbon enrichment with the sediments, the decreased $c B O D$ concentrations for both periods and for both emission scenarios might be due to the dilution effect. The dilution effect is more prominent in the higher emission scenarios and for the end-century period. Further, increased $T s$ would lead to a higher biodegradation rate (RK1, Table S8), thereby reducing the resulting $c B O D$ concentrations. At temporal scales, the decreases are more significant in mid-spring (e.g., April). However, due to earlier snow freshet, a lowered water yield in late-spring (e.g., May) has led to increased $C B O D$ concentrations. From a management point of view, the future $c B O D$ concentrations would never cross the limits set for both Salmonid and Cyprinid waters.

Considering the low future $c B O D$ concentrations (Figure $8 b$ ) and a significant increment in $T s$ (Figure 8a), the changes in $D O$ (Figure $8 \mathrm{~b}$ ) are as expected. The $D O$ concentrations would decrease, at the most extreme case (higher emission scenario and end-century period) by $10 \%$. However, even with the reductions in $D O$ concentrations, the net $D O$ levels at this reach of the river would remain slightly higher than the objective level set by the Alberta Environment $\left(6.5 \mathrm{mgO}_{2} / \mathrm{l}\right.$, Table 3).

Similarly, concerning the $T N$ and $T P$ concentrations $(T N$ : Figure 8d and TP: Figure 8e) while significant increases (> $150 \%$ ) in $T N$ concentrations at almost all months are observed, the case for the $T P$ concentrations, however, is projected to be heterogeneous. In the case of $T N$, the increases are higher in late-spring (e.g., May) due to the lower water yield as a result of earlier spring freshet, and in earlier summer months (e.g. June, July) due to increased sediment associated organic nitrogen loading from sub-basins. A similar situation for the $T P$ has also been observed in the month of May. However, in the summer months, increased sediment associated organic phosphorus loadings from sub-basins seems to be diluted by the projected increases in water yield, thereby decreasing the 

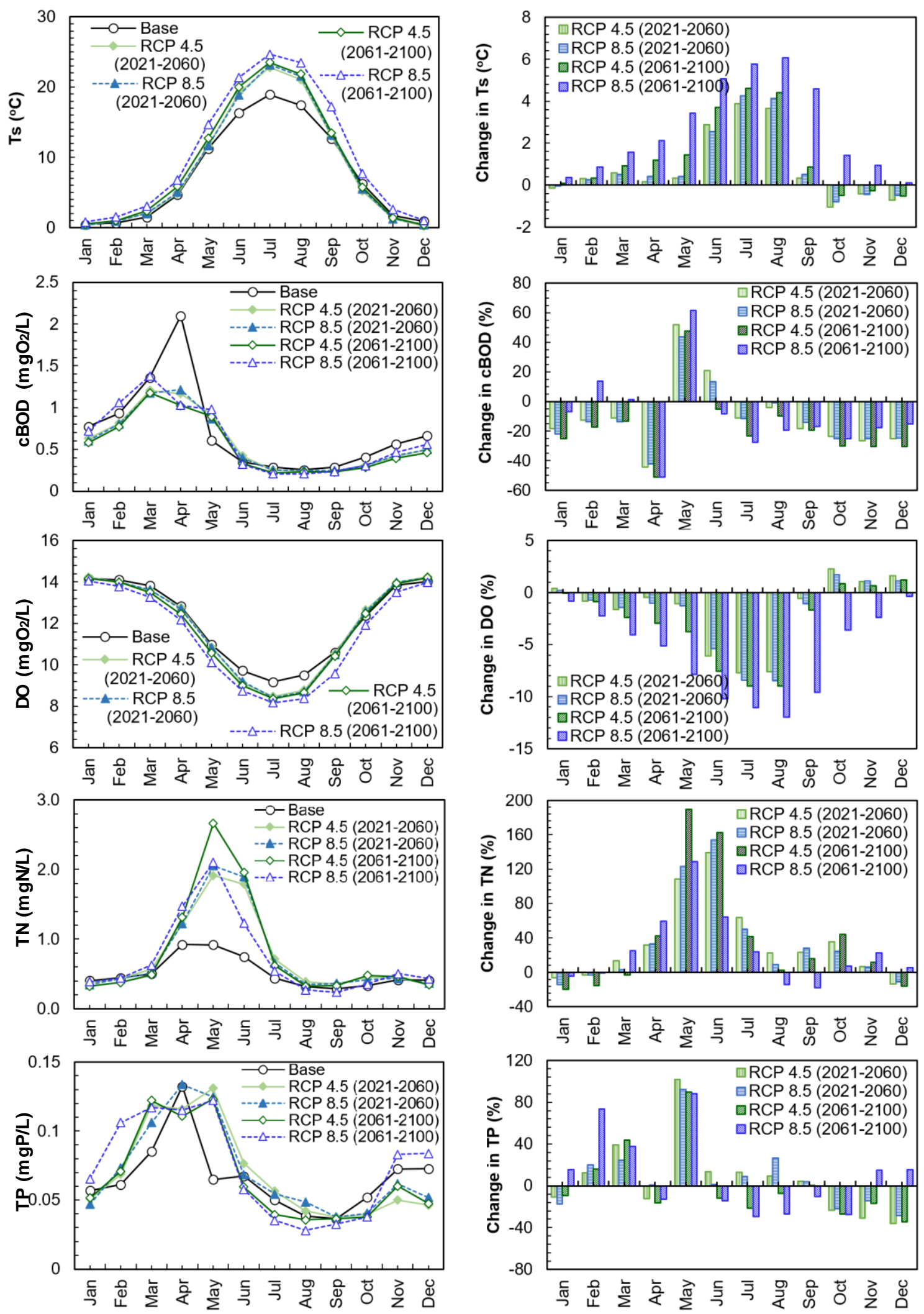

Figure 8. Comparison of monthly averaged absolute (stream water temperature- $T$ ) ) or percentage $(c B O D, D O, T N$ and $T P$ ) change in the concentrations of several water quality variables at Athabasca river u/s Fort McMurray (\#AB07CC0030) in base period (1983-2013) and future (2040's and 2080's) periods, and in two emission scenarios (RCP 4.5 and 8.5).

resulting $T P$ concentrations. From a management point of 
resulting $T P$ concentrations. From a management point of view, it is clear that the limit set for $T N$ by Alberta Environment \& Parks (1.0 mgN/L, Table 3) would be only exceeded in late spring and in the summer months. As for $T P$, the situation is severe only in the spring months of the midcentury period. However, the monthly averaged $T P$ concentrations tend to exceed the limit $(0.05 \mathrm{mgP} / \mathrm{L}$, Table 3$)$ quite frequently, especially during the winter, spring and autumn months. It is only during the summer months that the dilution effect would result in concentrations, which are lower than the objective level.

\subsubsection{Water Quality Index Calculation}

The water quality index (WQI) calculated using different water quality aspects (Equation 4), and scores (Table 3) shows that the river reaches in the headwater regions, in the base period, have generally a good to excellent water quality index. At the foothill region, the reaches receiving runoff from agricultural areas have a fair to marginal water quality index. However, the rest of the reaches have a good to excellent water quality index. A similar situation has been observed in the prairie and Lesser Slave regions, highlighting the role of agricultural runoff in impairing the water quality status of the river. The impairments tend to propagate in the downstream reaches of the river. The WQI tends to improve in further downstream reaches after they receive rather good to excellent quality of water from the northeast tributary (the Clearwater river) reaches. The water quality index tends to further degrade in future periods, especially in the higher emission scenario and in the end-century period, by scores greater than10. Such degradation is more prominent in the prairie region where the agricultural activities are the highest. This is primarily due to decreases in the $D O$ levels as a result of increases in $T s$ (driven by marked increases in temperature, Table S5), and increases in $T N$ and $T P$ loadings from agricultural areas (Table 6). However, in some reaches, especially those in the headwater and boreal plain regions, slight improvements (by a score of 2 or more) are evident in the future, driven mainly by the dilution effect of higher water yields in these regions (Table S5).

\subsection{Effectiveness of Management Scenarios}

As expected, agricultural areas are the main source of pollutants and nutrients impairing the water quality status of the river in future. As a result, several management scenarios have been formulated, as outlined in Section 2.5.2. They include controlling point (scenario A) and diffused (scenario B) pollution sources. Figure 10 shows the improvements on the concentrations of different water quality variables at the Athabasca river u/s Fort McMurray.

From the plots, it is clear that controlling diffused pollution sources (scenario B) is more effective by far than imposing limits on the point sources (scenario A). This is expected, as effluents from point sources contribute only a small fraction to the total streamflow at this section of the river. By imposing limits on point source effluents, slight improvements (about $5 \%$ ) have been achieved in $c B O D$ concentrations, while improvements on the $D O$ concentrations are

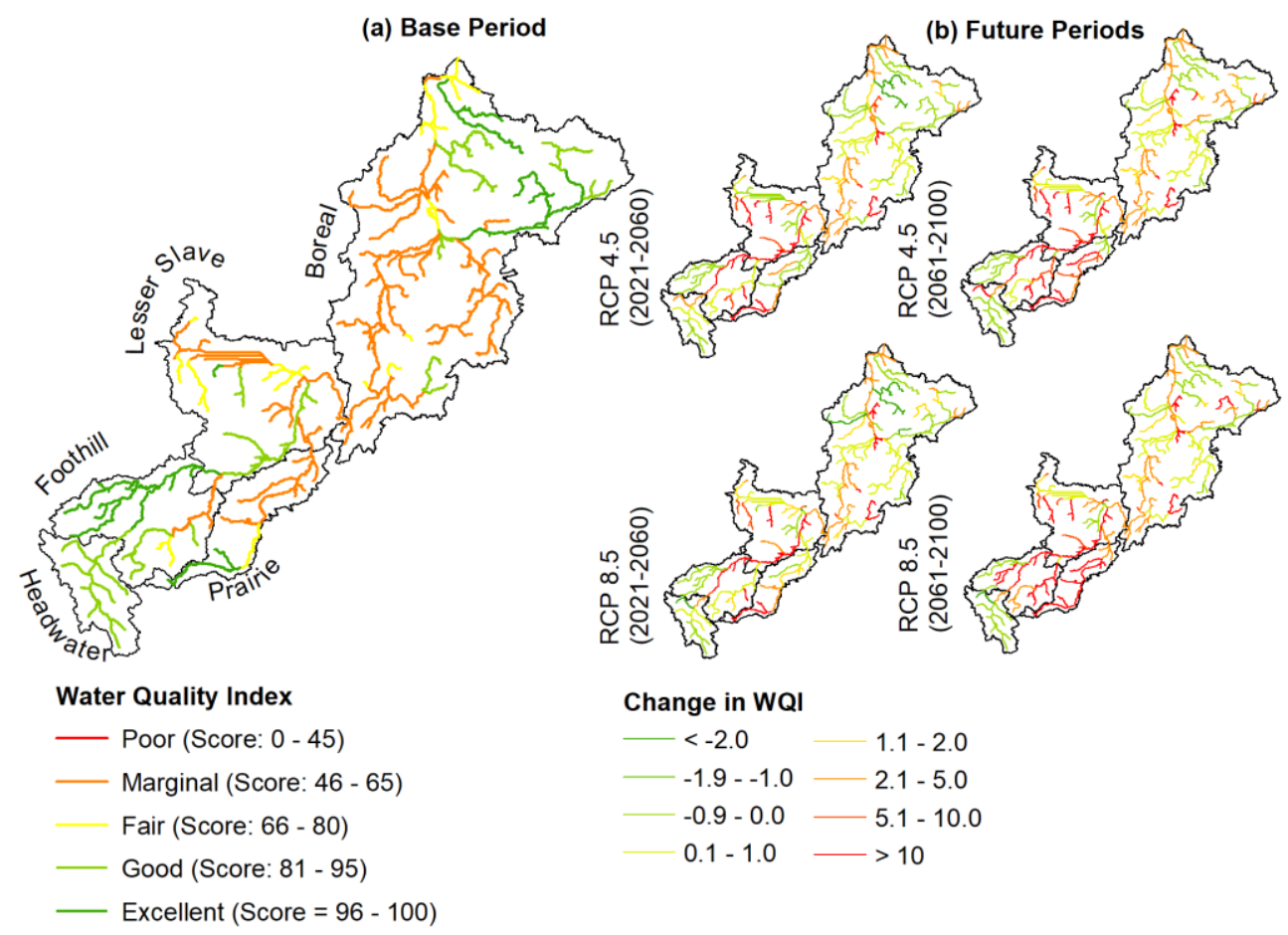

Figure 9. (a) Water Quality Index (WQI) of river reaches of Athabasca River Basin (ARB) in base period; (b) absolute changes in the WQI in two emission scenarios and in mid- and late-century periods, relative to base period (1983-2013). 
virtually zero. However, the scenario would have significant improvements $(\sim 20 \%)$ on $T P$ concentrations. This indicates that the point source effluents are laden with higher phosphorus levels than the limits imposed in EU (1991). Evidently, such small improvements resulting from scenario A, are not enough to increase the water quality index of the river reaches significantly (Figure 11). However, controlling various forms of diffused pollution sources (reducing fertilizer application in agricultural areas and pasture land-use; managing manure at rangelands, and adopting terrace farming) has led to significant improvements in the concentrations of all water quality variables except the DO (Figure 10). The improvements have duly been reflected in the water quality index. In general, the significant improvements ( $c B O D$ reduction by $>40 \%, T N$ reduction by $\sim 20 \%$, and $T P$ reduction by $>60 \%$ ) are observed in the higher emission scenarios and in the late-century periods. While we did not present the individual effects of each of the sub-scenarios taken within the scenario $\mathrm{B}$, it is found that adopting terrace farming would be the most effective. Practicing terrace farming has not only reduced the surface runoff, but has also reduced sediment yield significantly, thereby decreasing the sediment associated pollutant $(c B O D)$ and nutrients (TP and $T N$ ) loadings. However, limiting fertilizer application rates to the lower end of the recommended ranges (AGRI-FACTS, 2013) has also led to significant reduction in the loadings of soluble forms of nutrients. As observed for scenario A, the improvements in $D O$ concentrations are rather low, indicating that the DO dynamics in the $\mathrm{ARB}$ are less influenced by pollution and nutrients levels.

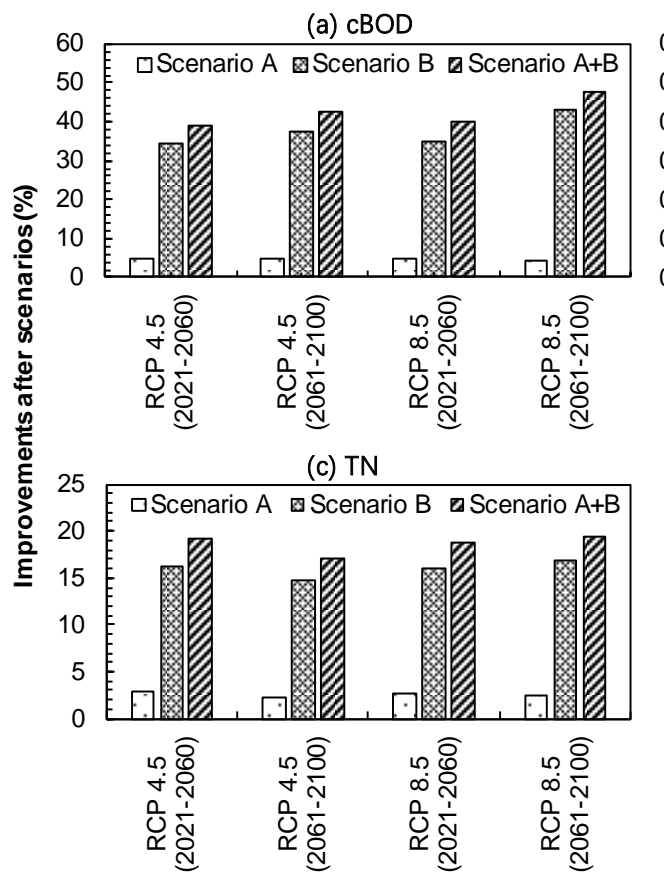

Significant improvements on WQI score due to the combined effect of both scenarios, at prairie and Lesser Slave regions where the agricultural activities are the highest, could be achieved. The improvements seem to be propagated in the downstream reaches of the main river. At other tributaries, which do not receive runoff from agricultural areas, the WQI score, as expected, remained unchanged.

\section{Conclusions}

Cold climate regions serve a multitude of ecosystem services such as terrestrial carbon storage, climate regulation, water retention and infiltration, and biodiversity. Under a changing climate, these regions could be more vulnerable than others because some special geographic features of the regions, such as glaciers, freezing soils and peatland, are more sensitive to changes in temperature and precipitation. This can impose serious threats on the water resources, sustainable goods production and ecosystem services that depend on regional water quality. However, it is still unknown how the changing climate would affect water resources, ecosystems and biodiversity because of the complex hydrological and biogeochemical processes involved. Particularly, in cold climate region watersheds, glaciers and freezing land lead to further complexity. In order to manage these watersheds properly, it is imperative that the complex hydrological and biogeochemical processes of these regions are well understood. As such, in this study, we focused on quantifying the impacts of climate change on the water quality status of a cold climate
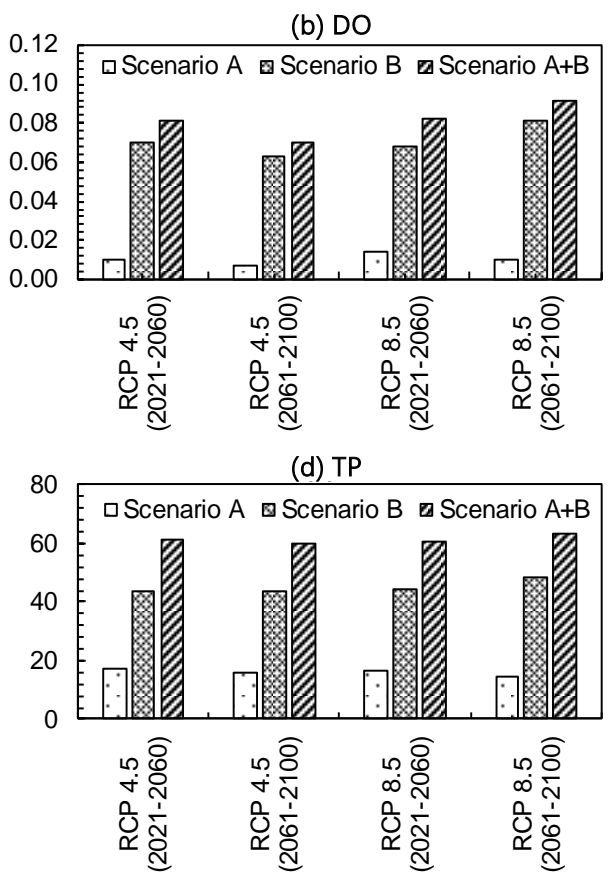

Future Climate Periods and Emission Scenarios

Figure 10. Percentage improvements (decrease in concentration of (a) carbonaceous biochemical oxygen demand (cBOD), (c) total nitrogen (TN) and (d) total phosphorus (TP), and increase in concentration of (b) dissolved oxygen (DO)) in annual averaged concentration of different water quality components against tested management scenarios at Athabasca river $\mathrm{u} / \mathrm{s}$ of Fort McMurray (\#AB07CC0030). 

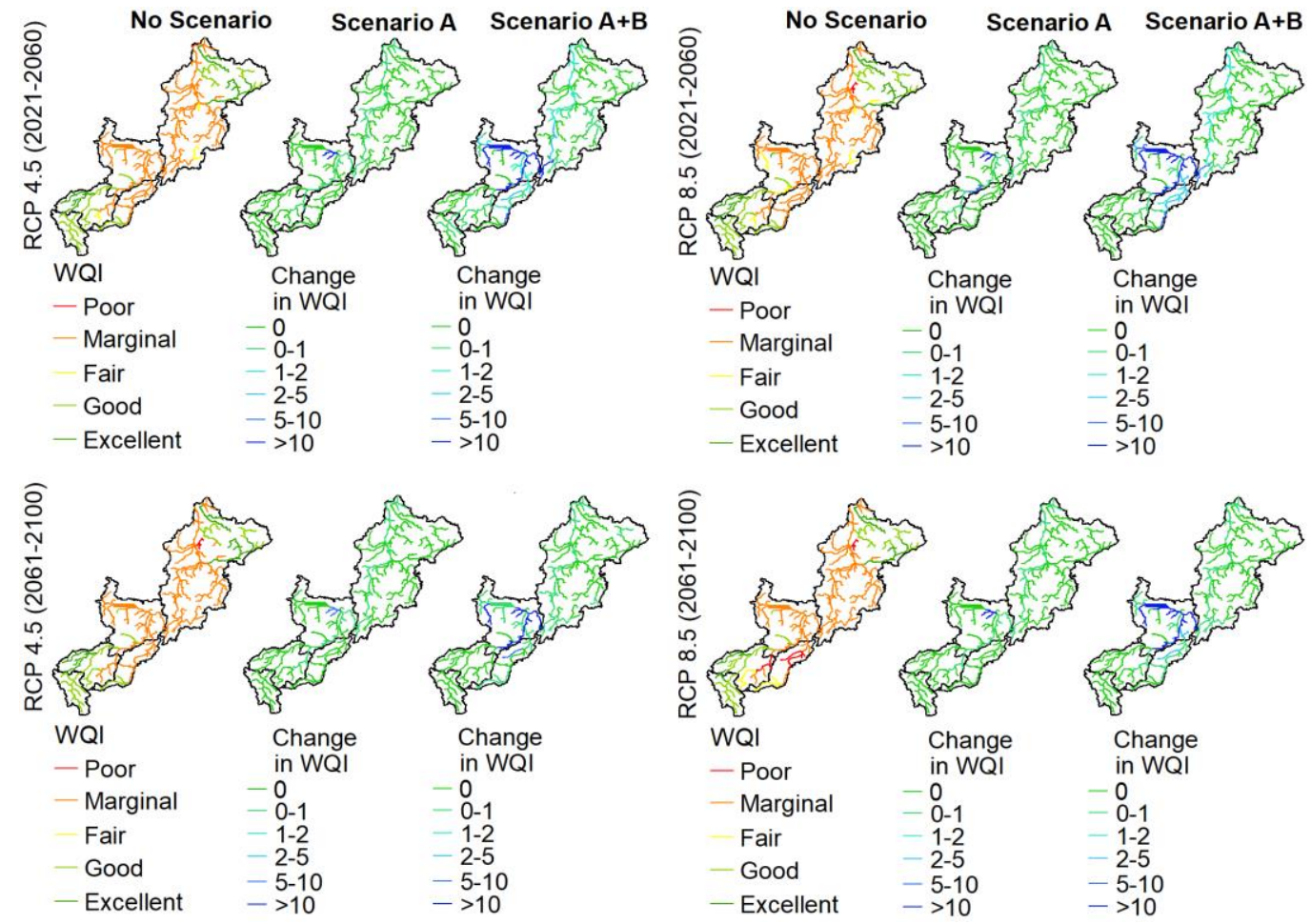

Figure 11. Improvements due to tested management scenarios on Water Quality Index (WQI) of river reaches of Athabasca River Basin (ARB) in two future (2040's and 2080's) periods and in two emission scenarios (RCP 4.5 and 8.5).

region watershed - the Athabasca River Basin (ARB) in Canada, and testing alternative management options in improving water quality status. As such, we modified specific water quality related processes of a process-based model-Soil and Water Assessment Tool (SWAT) with a view of better representing the reality of cold climate regions. A SWAT model of the basin was built-up followed up by a multi-site and multiobjective (streamflow, sediment and water quality) calibration, validation and uncertainty analysis in a base period (1983 2013). The calibrated and validated model was then fed with high spatial resolution $(25 \times 25 \mathrm{~km})$ daily future climate data - the CanRCM, which is tailor-made for applications in Canada. We considered two IPCC emission scenarios (RCP 4.5 and 8.5) and two future periods (mid-century: 2021 2060 and end-century: $2061 \sim 2100$ ).

Results indicated that the modified SWAT model improved the stream water temperature $(T S)$ and dissolved oxygen $(D O)$ simulations significantly, justifying the modifications. The modified SWAT model is also able to simulate the dynamics of other water quality variables (carbonaceous biochemical oxygen demand $-c B O D$, total nitrogen $-T N$ and phosphorus $-T P$ ) with a wide range of accuracy (very good to satisfactory) at selected stations across the basin in the base period. With an annual average $T N$ and $T P$ yield rate of 11.16 $\mathrm{kgN} / \mathrm{ha}$ and $2.88 \mathrm{kgP} / \mathrm{ha}$, respectively, the agriculture areas are the main source of nutrients in the base period, and as a consequence, the river reaches downstream of these areas have poor water quality status. The situation would be further exacerbated in the future with yields reaching up to $16.52 \mathrm{kgN} / \mathrm{ha}$ and $4.89 \mathrm{kgP} / \mathrm{ha}$, leading to further impairment in the water quality status of the downstream reaches. In general, the future climate of the ARB is projected to be warmer and wetter, relative to the base period. These changes have led to decreased $c B O D$ concentrations, mainly due to dilution and increased degradation. Further, a warmer future climate increased the $T s$ which in turn reduced the $D O$ concentrations. Moreover, while a wetter future climate increased $T N$ concentrations mainly due to increased sediment associated nitrogen, the TP concentrations, on average, decreased due to a dominating dilution effect. On testing alternative management scenarios, it is found that controlling diffused pollution sources especially by adopting terrace farming, is the most effective. The combined measures (controlling both point and diffused sources of pollution) have resulted in a significant reduction in future pollutant and nutrients concentrations $(\sim 50 \%$ on $c B O D, 20 \%$ on $T N$ and $60 \%$ on $T P$ ). This has led to the partial restoration of the ecological status of some reaches of the basin, especially those immediately downstream of agricultural areas. Generally, it can be concluded that the modified SWAT model can be applied to other cold climate regions and the results of the tested management options can be translated in to a holistic watershed management of the ARB so that the goods and services that depend on a regular supply of good quality water would not be impacted in future.

Acknowledgments. The authors would like to thank the Alberta Economic Development and Trade for the Campus Alberta Innovates Program Research Chair (No. RCP-12-001-BCAIP). We would also 
like to thank Dr. Xinzhong Du for processing the climate change data and Mr. Jim Sellers for the proofreading. Modified SWAT source code will be made available upon request.

\section{References}

AAFC(2002). RUSLEFAC: Revised Universal Soil Loss Equation for Application in Canada. A Handbook for Estimating Soil Loss from Water Erosion in Canada, Agriculture and Agri-Food Canada, Ontario, Canada.

AAFC(2013). Annual Crop Inventory, AAFC (Eds.). Agriculture and Agri-Food (AAFC), Ontario, Canada.

Abbaspour, K.C., Johnson, C.A., and van Genuchten, M.T. (2004). Estimating uncertain flow and transport parameters using a sequential uncertainty fitting procedure, Vadose Zone J., 3(4), 13401352. https://doi.org/10.2136/vzj2004.1340

Abbaspour K.C., Yang J., Maximov I., Siber R., Bogner K., Mieleitner J., Zobrist J., and Srinivasan R. (2007). Modelling hydrology and water quality in the pre-alpine/alpine Thur watershed using SWAT. J. Hydro., 333(2-4), 413-430. https://doi.org/ 10.1016/j.jhydrol.2006.09.014

AEP(2016). Surface Water Quality Data, in AEP (Eds.). Alberta Environment and Parks (AEP), Edmonton, Canada.

AEP (2017). Alberta River Water Quality Index Results (2013-2014). Alberta Environment and Parks (AEP), Edmonton, Canada.

AGRI-FACTS (1998). Grazing Tame Pastures Effectively, in AGRIFACTS (Eds.), Alberta Agriculture and Forestry, Edmonton, Canada.

AGRI-FACTS (2004). Alberta Fertilizer Guide, in AGRI-FACTS (Eds.), Alberta Agriculture and Forestry, Edmonton, Canada.

AGRI-FACTS (2005a). Fertilizing Grass for Hay and Pasture, in AGRI-FACTS (Eds.), Alberta Agriculture and Forestry, Edmonton, Canada.

AGRI-FACTS (2005b). Perennial Forage Establishment in Alberta, In AGRI-FACTS (Eds.), Alberta Agriculture and Forestry, Edmonton, Canada.

AGRI-FACTS (2013). Dryland Agronomic Management of Soft White Spring Wheat and Canada Prairie Spring Wheat in Alberta, in AGRI-FACTS (Eds.), Alberta Agriculture and Forestry, Edmonton, Canada.

Akomeah, E. and Lindenschmidt, K. E. (2017). Seasonal Variation in Sediment Oxygen Demand in a Northern Chained River-Lake System. Water, 9(4). https://doi.org/10.3390/w9040254

Alberta-Environment (1982). Agricultural Runoff and Lake Water Quality. Alberta Environment, Edmonton.

Andrey, J., Kertland, P., and Warren, F.J. (2014). Water and Transportation Infrastructure, in Warren, F.J., Lemmen, D.S. (Eds.), Canada in a Changing Climate: Sector Perspectives on Impacts and Adaptation, Government of Canada, Ottwa.

APHA (1985). Standard methods for the examination of water and wastewater, American Public Health Association, Washington DC.

Arnold, J.G., Kiniry, J.R., Srinivasan, R., Williams, J.R., Haney, E.B., and Neitsch, S.L. (2011). Soil and Water Assessment Tool Input/ Output File Documentation, Version 2009, Texas Water Resources Institute Technical Report No. 365. Texas A\&M University System, College Station, Texas 77843-2118.

Arnold, J.G., Moriasi, D.N., Gassman, P.W., Abbaspour, K.C., White, M.J., Srinivasan, R., Santhi, C., Harmel, R.D., Van Griensven, A., Van Liew, M.W., and Kannan, N. (2012). SWAT: Model use, calibration, and validation. Transactions of the ASABE, 55(4), 1491-1508. https://doi.org/10.13031/2013.42256

Arnold, J.G., Srinivasan, R., Muttiah, R.S., and Williams, J.R. (1998). Large area hydrologic modeling and assessment part I: Model development. J. Am. Water Resour. Assoc., 34(1), 73-89. https:// doi.org/10.1111/j.1752-1688.1998.tb05961.x
AWC (2011). Athabasca Watershed Council - State of the Watershed Report: Phase 1. Athabasca Watershed Council, Hilton, Alberta.

AWC (2013). State of the Watershed Report: Phase 3 - Water Quantity and Basic Water Quality in the Athabasca Watershed. Athabasca Watershed Council, Hilton, Alberta.

AWC (2014). Athabasca State of the Watershed Assessment Phase 4: Organic Compounds in Surface Water and Sediments, and Trace Metals in Sediments. Athabasca Watershed Council, Hilton, Alberta.

Bennett, N.D., Croke, B.F.W., Guariso, G., Guillaume, J.H.A., Hamilton, S.H., Jakeman, A.J., Marsili-Libelli, S., Newham, L.T. H., Norton, J.P., Perrin, C., Pierce, S.A., Robson, B., Seppelt, R., Voinov, A.A., Fath, B.D., and Andreassian, V. (2013). Characterising performance of environmental models. Environmental Modelling \& Software 40, 1-20. https://doi.org/10.1016/j.envsoft. 2012.09.011

Boluwade, A. and Madramootoo, C. (2015). Determining the Influence of Land Use Change and Soil Heterogeneities on Discharge, Sediment and Phosphorus. J. Environ. Inf., 25(2). https:// doi.org/10.3808/jei.201500290

Broekhuizen, N., Park, J.B.K., McBride, G.B., and Craggs, R.J. (2012). Modification, calibration and verification of the IWA River Water Quality Model to simulate a pilot-scale high rate algal pond. Water Res., 46(9): 2911-2926. https://doi.org/10.1016/j.watres. 2012.03.011

Brown, L. and Barnwell, T. (1987). The enhanced stream water quality models QUAL2E and QUAL2E-UNCAS:Documenta-tion and User Manual, US EPA, Environmental Research Laboratory, Georgia, USA.

Bush, E.J., Loder, J.W., James, T.S., Mortsch, L.D. and Cohen, S.J. (2014). An Overview of Canada's Changing Climate. In Warren, F.J. and Lemmen, D.S. (Eds.), Changing Climate: Sector Perspectives on Impacts and Adaptation, Government of Canada, Ottawa, pp. 23-64.

Caissie, D. (2006). The thermal regime of rivers: a review. Freshw. Biol., 51(8), 1389-1406. https://doi.org/10.1111/j.1365-2427.20 06.01597.x

Campbell, I.D., D.G., D., Hunter, K.L., and Hyatt, K.D. (2014). Food Production, in Warren, F.J. and Lemmen, D.S. (Eds.), Changing Climate: Sector Perspectives on Impacts and Adapt-ation, Government of Canada, Ottwa, pp. 99-134.

Carlson, R.E. (1977). A trophic state index for lakes1. Limnol. Oceanogr., 22(2), 361-369. https://doi.org/10.4319/lo.1977.22.2.0361

Casey, R.J. (1990). Sediment Oxygen Demand during the Winter in the Athabasca River and the Wapiti Smoky River System, 1990. Alberta Environment, Standards and Approvals Division and Environment Assessment Division, Edmonton.

CFSR (2016). Climate Forecast System Reanalysis, in GWD-SWAT (Eds.), Global Weather Data for SWAT, Texas.

Cheng, G.H., Huang, G.H., Dong, C., Zhou, X., Zhu, J.X., and Xu, Y. (2017a). Climate classification through recursive multi-variate statistical inferences: a case study of the Athabasca River Basin, Canada. Int. J. Climatol., 37, 1001-1012. https://doi.org/10.1002/ joc. 5052

Cheng, G.H., Huang, G.H., Dong, C., Zhu, J.X., Zhou, X., and Yao, Y. (2017b). High-resolution projections of 21st century climate over the Athabasca River Basin through an integrated evaluation -classification-downscaling-based climate projection framework. $J$. Geophys. Res. (D Atmos.), 122(5), 2595-2615. https://doi.org/10. 1002/2016JD026158

Cheng, G. H., Huang, G. H., Dong, C., Zhu, J. X., Zhou, X., and Yao, Y. (2017c). An Evaluation of CMIP5 GCM Simulations over the Athabasca River Basin, Canada. River Res. Appl., 33(5), 823-843. https://doi.org/10.1002/rra.3136

Christensen, N.S. and Lettenmaier, D.P. (2007). A multimodel 
ensemble approach to assessment of climate change impacts on the hydrology and water resources of the Colorado River Basin. Hydrol. Earth Syst. Sci. Discuss., 11(4): 1417-1434. https://doi.org/ 10.5194/hess-11-1417-2007

Dodd, R.C., McMahon, G., and Stichter, S. (1992). Watershed planning in the Albemarle-Pamlico estuarine system, Report 1: Annual Average Nutrient Budgets. Department of Environment, Health and Natural Resources, Raleigh, North Carolina.

Dunne, T. and Black, R.D. (1970). Partial Area Contributions to Storm Runoff in a Small New England Watershed. Water Resour. Res., 6(5), 1296-1311. https://doi.org/10.1029/WR006i 005p01296

Easton, Z.M., Fuka, D.R., Walter, M.T., Cowan, D.M., Schneiderman, E.M., and Steenhuis, T.S. (2008). Re-conceptualizing the soil and water assessment tool (SWAT) model to predict runoff from variable source areas. J. of Hydrol., 348(3): 279-291. https:// doi.org/10.1016/j.jhydrol.2007.10.008

ECCC (2016). Climate data and scenarios for Canada: Synthesis of recent observation and modelling results, Environment and Climate Change Canada, Quebec, Canada.

ETCW (2010). Climate change impacts on water quality and biodiversity: Background Report for EEA European Environment State and Outlook Report 2010, European Topic Centre on Water, Litevská, Czech Republic.

EU (1991). Directive 1991/271/EC of the European Parliament and of the Council of 21 May 1991 concening urban waste water treatment. Official Journal of the European Communities, L135/40.

EU (2006). Directive 2006/44/EC of the European parliament and of the Council of 6 September 2006 on the quality of fresh waters needing protection or improvement in order to support fish life. Official Journal of the European Union, L264, 20-31.

Eum, H. I., Dibike, Y., and Prowse, T. (2017). Climate-induced alteration of hydrologic indicators in the Athabasca River Basin, Alberta, Canada. J. Hydrol., 544, 327-342. https://doi.org/10.10 16/j.jhydrol.2016.11.034

Eyzaguirre, J. and Warren, F.J. (2014). Adaptation: Linking Research and Practice, in Warren, F.J., Lemmen, D.S. (Eds.), Canada in a Changing Climate: Sector Perspectives on Impacts and Adaptation. Government of Canada, Ottwa.

Farammarzi, M., Abbaspour, K.C., Adamowicz, W.L., Lu W., Fennell, J., Zehnder, A.J.B., and Goss, G.G.(2017). Uncertainty based assessment of dynamic freshwater scarcity in semi-arid watersheds of Alberta, Canada. J. Hydrol.: Reg. Stud., 9: 48-68. https:// doi.org/10.1016/j.ejrh.2016.11.003

GoC (2014). Canada in a Changing Climate: Sector Perspectives on Impacts and Adaptation, Climate Change Impacts and Adaptation Division, Natural Resources Canada, Ottawa.

GoC (2016). Environment and Natural Resources: Weather, Climate and Hazard, in GoC (Eds.). Government of Canada (GoC), New Brunswick, Canada.

Golder-Associates (2009). Hydro-Climate Model Selection and Application on the Athabasca and Beaver River Basins, Oil Sands Environmental Management Division. Alberta Environment, Calgary, Alberta, Canada.

Goolsby, D.A. (2000). Mississippi Basin nitrogen flux believed to cause Gulf hypoxia. Eos Trans. Am. Geophy. Union, 81(29), 321-327. https://doi.org/10.1029/00EO00244

Haan, C.T., Barfield, B.J., and Hayes, J.C. (1994). Design hydrologyand sedimentlogy for small catchments. Academic Press, New York.

Hawkins, E. and Sutton, R. (2009). The Potential to Narrow Uncertainty in Regional Climate Predictions. Bull. Am. Meteorol. Soc., 90(8), 1095-1107. https://doi.org/10.1175/2009 BAMS2607.1

He, J. (2017). Probabilistic Evaluation of Causal Relationship between Variables for Water Quality Management. J.Envrion. Inf.,
28(2): 110-119. https://doi.org/10.3808/jei.201600353

HydroQual-Consultants (1989). Athabasca River Winter Re-aeration Investigation. Alberta Environment, Calgary, Canada.

IPCC (2007). Climate Change 2007: Impacts, Adaptation and Vulnerability. Contribution of Working Group II to the Fourth Assessment Report of the Intergovernmental Panel on Climate Change. Cambridge University Press, Cambridge, U.K.

IPCC (2014). Climate Change 2014: Synthesis Report. Contri-bution of Working Groups I, II and III to the Fifth Assessment Report of the Intergovernmental Panel on Climate Change. IPCC, IPCC.

Jarvis, A., Reuter, H.I., Nelson, A., and Guevara, E. (2008). Holefilled SRTM for the globe Version 4, available from the CGIARCSI SRTM 90m Database. Consultative Group for International Agricultural Research (CGIAR), Montpellier, France.

Kemanian, A.R. and Stöckle, C.O. (2010). C-Farm: A simple model to evaluate the carbon balance of soil profiles. Eur. J. Agron., 32(1),22-29. https://doi.org/10.1016/j.eja.2009.08.003

Kerkhoven, E. and Gan, T.Y. (2011). Differences and sensitivities in potential hydrologic impact of climate change to regional-scale Athabasca and Fraser River basins of the leeward and windward sides of the Canadian Rocky Mountains respectively. Clim. Change, 106(4), 583-607. https://doi.org/10.1007/s10584-010-9958-7

Laanaya, F., St-Hilaire, A., and Gloaguen, E.(2017). Water temperature modelling: comparison between the generalized additive model, logistic, residuals regression and linear regression models. Hydrol. Sci. J, 1-16. https://doi.org/10.1080/02626667. 2016.1246799

Lemmen, D.S., Johnston, M., Ste-Marie, C., and Pearce, T. (2014). Natural Resources in Warren, F.J., Lemmen, D.S. (Eds.), Canada in a Changing Climate: Sector Perspectives on Impacts and Adaptation, Government of Canada, Ottwa, pp. 65-98.

Leong, D.N.S. and Donner, S.D. (2015). Climate change impacts on streamflow availability for the Athabasca Oil Sands. Clim. Change, 133(4), 651-663. https://doi.org/10.1007/s10584-015-1479-y

Loveland, T. R., Reed, B. C., Brown, J. F., Ohlen, D. O., Zhu Z., Yang L., and Merchant, J. W. (2000). Development of a global land cover characteristics database and IGBP DISCover from $1 \mathrm{~km}$ AVHRR data. Int. J. Remote Sens., 21(6-7), 1303-1330. https:// doi.org/10.1080/014311600210191

Marzadri, A., Tonina, D., and Bellin, A. (2013). Quantifying the importance of daily stream water temperature fluctuations on the hyporheic thermal regime: Implication for dissolved oxygen dynamics. J. Hydro., 507, 241-248. https://doi.org/10.1016/j.jh ydrol.2013.10.030

McFarland, A.M.S. and Hauck, L.M. (2001). Determining Nutrient Export Coefficients and Source Loading Uncertainty using In-stream Monitoring Data. J. Am. Water Resour. Assoc., 37(1), 223-236. https://doi.org/10.1111/j.1752-1688.2001.tb05 488.x

MDEQ (2001). Nutrient Management Plan and Total Maximum Daily Load for Flathead Lake, Montana. Montona, Canada.

Menzel, R.G.(1980). Enrichment ratios for water quality modeling. USDA Conservation Research Report 26, Washington, DC, USA.

Mohseni, O. and Stefan, H.G. (1999). Stream temperature/air temperature relationship: a physical interpretation. J. Hydrol., 218(3-4), 128-141. https://doi.org/10.1016/S0022-1694(99)00 034-7

Mohseni, O., Stefan, H.G., and Erickson, T.R., 1998. A nonlinear regression model for weekly stream temperatures. Water Resour. Res., 34(10), 2685-2692. https://doi.org/10.1029/98WR01877

Moriasi, D.N. (2007). Model evaluation guidelines for systematic quantification of accuracy in watershed simulations. Trans. ASABE, 50(3), 885-900. https://doi.org/10.13031/2013.23153

Moriasi, D.N., Gitau, M.W., Pai, N., and Daggupati, P. (2015). Hydrologic and Water Quality Models: Performance Measures and Evaluation Criteria. Trans. ASABE, 58(6), 1763-1785. https://doi. 
org/10.13031/trans.58.10715

Murdock, T.Q., Cannon, A.J., and Sobie, S.R. (2013). Statistical downscaling of future climate projections. Pacific Climate Impacts Consortium (PCIC), Victoria, British Columbia, Canada.

Neitsch, S.L., Arnold, J.G., Kiniry, J.R., and Williams, J.R. (2011). Soil \& Water Assessment Tool Theoretical Documentation, Version 2009, Grassland Soil and Water Research Laboratory-Agricultural Research Service, Blackland Research Center-Texas AgriLife Research.

Nicholaichuk, W. and Read, D.W.L. (1978). Nutrient Runoff from Fertilized and Unfertilized Fields in Western Canada. Can. J. Environ. Qual., 7(4): 542-544. https://doi.org/10.2134/jeq1978. $00472425000700040015 \mathrm{x}$

Northern River Basins Study (1993). Sediment Oxygen Demand Investigations: Athabasca River, January to March, 1992. Northern River Basins Study project report, Monenco, Canada.

Olness, A., Smith, S.J., Rhoades, E.D., Menzel, R.G. (1975). Nutrient and Sediment Discharge from Agricultural Watersheds in Oklahoma. J. Environ. Qual., 4(331-336). https://doi.org/10.2134/jeq $1975.00472425000400030009 x$

Pietroniro, A., Chambers, P.A., and Ferguson, M.E. (1998). Application of a Dissolved Oxygen Model to an Ice-covered River. Can. Water Resour. J., 23(4), 351-368. https://doi.org/10.4296/cwrj2304351

Prowse, T.D. (2001). River-Ice Ecology. I: Hydrologic, Geomorphic, and Water-Quality Aspects. J. Cold Regions Eng., 15(1), 1-16. https://doi.org/10.1061/(ASCE)0887-381X(2001) 15:1(1)

Reichert, P., Borchardt, D., Henze, M., Rauch, W., Shanahan, P., Somlyódy, L., and Vanrolleghem. P.A. (2001). River Water Quality Model No.1. IWA Publishing, London, UK.

Scinocca, J. F., Kharin, V. V., Jiao, Y., Qian, M. W., Lazare, M., Solheim, L., Flato, G. M., Biner, S., Desgagne, M., AND Dugas, B. (2015). Coordinated Global and Regional Climate Modeling. $J$. Clim., 29(1), 17-35. https://doi.org/10.1175/JCLI-D-15-016 1.1

Shakibaeinia, A., Kashyap, S., Dibike, Y.B., and Prowse, T.D. (2016). An integrated numerical framework for water quality modelling in cold-region rivers: A case of the lower Athabasca River. Sci. Total Environ., 569-570, 634-646. https://doi.org/10.1016/j.scitotenv. 2016.06.151

Shrestha, N.K., Du, X., and Wang, J. (2017a). Assessing climate change impacts on fresh water resources of the Athabasca River Basin, Canada. Sci. Total Environ., 601-602, 425-440. https:// doi.org/10.1016/j.scitotenv.2017.05.013

Shrestha, N.K., Leta, O.T., and Bauwens, W. (2017b). Development of RWQM1-based integrated water quality model in OpenMI with application to the River Zenne, Belgium. Hydrol. Sci. J., 62(5), 774-799. https://doi.org/10.1080/026266 67.2016.1261143

Shrestha, N. K., Leta, O. T., Fraine, B. D., Garcia-Arimsen, T., Outtara, N. K., Servais, P., Griensven, A.V., and Bauwens, W. (2013). Modelling Escherichia coli dynamics in the river Zenne (Belgium) using an OpenMI based integrated model. J. Hydroinf., 16(2), 354-374. https://doi.org/10.2166/hydro.2013. 171

Shrestha, N.K., Leta, O.T., De Fraine, B., van Griensven, A., and Bauwens, W. (2013a). OpenMI-based integrated sediment transport modelling of the river Zenne, Belgium. Environ. Model. Software, 47, 193-206. https://doi.org/10.1016/j.envsoft.2013.05.004

Shrestha, N.K., Leta, O.T., Nossent, J., Van Griensven, A., and Bauwens, W. (2013b). Development of a stream water temperature model as a component model for OpenMI based integrated modelling of river Zenne, Belgium, 2nd OpenWater symposium and workshops, 16th-17th September. Vrije Universiteit Brussels, Brussels, Belgium.

Shrestha, N.K. and Wang, J. (2018). Predicting sediment yield and transport dynamics of a cold climate region watershed in changing climate. Sci. Total Environ., 625, 1030-1045. https://doi.org/10. 1016/j.scitotenv.2017.12.347

SLCWG (2010). Soil Landscapes of Canada version 3.2: digital map and database at 1:1 million scale, in SLCWG-AAFC (Eds.). Soil Landscapes of Canada Working Group (SLCWG), Agriculture and Agri-Food Canada (AAFC), Ontario, Canada.

Strauch, M., Otto, R., and Volk, M. (2015). HRU aggregation and its effects on model outputs. 2015 Internation SWAT Conference, Sardinia, Italy.

Terry, A.J., Sadeghian, A., and Lindenschmidt, K. E. (2017). Modelling Dissolved Oxygen/Sediment Oxygen Demand under Ice in a Shallow Eutrophic Prairie Reservoir. Water, 9(2). https://doi.org/10.3390/w9020131

Teutschbein, C. and Seibert, J. (2012). Bias correction of regional climate model simulations for hydrological climate-change impact studies: Review and evaluation of different methods. J. Hydrol., 456-457, 12-29. https://doi.org/10.1016/j.jhydrol.201 2.05.052

Thomann, R.V. and Mueller, J.A. (1987). Principles of surface water quality modeling and control. Harper \& Row Publishers, New York.

Tiruneh, B.A. (2004). Modelling Water Quality Using Soil and Water Assessment Tool (SWAT): A Case Study in Lake Nivasha Basin, Kenya. International Institute for Geo-information Science and Earth Observation Enschide, The Netherlands.

Tong, S.T.Y., Liu, A.J. and Goodrich, J.A. (2007). Climate Change Impacts on Nutrient and Sediment Loads in a Midwestern Agricultural Watershed. J. Environ. Inf., 9(1), 18-28. https://doi. org/10.3808/jei.200700084

Toth, B., Pietroniro, A., Conly, F.M., and Kouwen, N. (2006). Modelling climate change impacts in the Peace and Athabasca catchment and delta: I-hydrological model application. Hydrol. Process., 20(19), 4197-4214. https://doi.org/10.1002/h yp.6426

Walling, D. (2009). The Impacts of Global Change on Erosion and Sediment Transport by Rivers: Current Progress and Future Challenges, UNESCO, Paris, France.

Warren, F.J. and Lemmen, D.S. (2014). Synthesis, in Warren, F.J. and Lemmen, D.S. (Eds.), Canada in a Changing Climate: Sector Perspectives on Impacts and Adaptation. Government of Canada, Ottawa, pp. 1-18.

Watson, B.M., McKeown, R.A., Putz, G., and MacDonald, J.D. (2008). Modification of SWAT for modelling streamflow from forested watersheds on the Canadian Boreal PlainThis article is one of a selection of papers published in this Supplement from the Forest Watershed and Riparian Disturbance (FORWARD) Project. J. Environ. Eng. Sci., 7(S1): 145-159. https://doi.org/10.1139/ S09-003

Webb, B.W., Clack, P.D., and Walling, D.E. (2003). Water-air temperature relationships in a Devon river system and the role of flow. Hydrol. Process., 17(15), 3069-3084. https://doi.org/10.1002/ hyp. 1280

Webb, B.W., Hannah, D.M., Moore, R.D., Brown, L.E., and Nobilis, F. (2008). Recent advances in stream and river temperature research. Hydrol. Process., 22(7), 902-918. https://doi.org/10. 1002/hyp.6994

Wilby, R. L., Wigley, T. M. L., Conway, D., Jones, P. D., Hewitson, B. C., Main, J., and Wilks, D.S. (1998). Statistical downscaling of general circulation model output: A comparison of methods. Water Resour. Res., 34(11), 2995-3008. https://doi.org/10.1029/98WR02577

WSC (2016). Historical Hydrometric Data, in WSC-ECCC (Eds.). Water Survey of Canada (WSC), Environment and Climate Change Canada (ECCC), New Brunswick.

Xia, X.H., Wu, Q., Mou, X.L., and Lai, Y.J. (2015). Potential Impacts of Climate Change on the Water Quality of Different Water Bodies. J. Environ. Inf., 25(2), 85-98. https://doi.org/10.3808/jei.201400263 